\title{
Diabetic phenotype in mouse and humans with $\beta$-amyloid pathology reduces the number of microglia around $\beta$-amyloid plaques
}

Teemu Natunen ${ }^{1 *}$, Henna Martiskainen ${ }^{1}{ }^{*}$, Mikael Marttinen ${ }^{1}$, Sami Gabbouj ${ }^{1}$, Hennariikka Koivisto $^{2}$, Susanna Kemppainen ${ }^{1}$, Satu Kaipainen ${ }^{2}$, Mari Takalo ${ }^{1}$, Helena Svobodová3, Luukas

Leppänen ${ }^{1}$, Benjam Kemiläinen ${ }^{4}$, Simo Ryhänen ${ }^{1}$, Teemu Kuulasmaa ${ }^{1}$, Eija Rahunen ${ }^{1}$, Sisko Juutinen $^{1}$, Petra Mäkinen ${ }^{1}$, Pasi Miettinen ${ }^{2}$, Tuomas Rauramaa ${ }^{5}$, Jussi Pihlajamäki ${ }^{6}$, Annakaisa Haapasalo $^{2}$, Ville Leinonen ${ }^{4}$, Heikki Tanila $^{2} *$ Mikko Hiltunen $^{1 *}$

${ }^{1}$ Institute of Biomedicine, University of Eastern Finland, Kuopio, Finland

${ }^{2}$ A. I. Virtanen Institute for Molecular Sciences, University of Eastern Finland, Kuopio, Finland

${ }^{3}$ Department of simulation and virtual medical education, Faculty of Medicine, Comenius University, Bratislava, Slovak Republic

${ }^{4}$ Department of Neurosurgery, Kuopio University Hospital and Institute of Clinical Medicine, Unit of Neurosurgery, University of Eastern Finland, Kuopio, Finland

${ }^{5}$ Department of Pathology, Kuopio University Hospital, Finland and Institute of Clinical Medicine, Unit of Pathology, University of Eastern Finland, Kuopio, Finland

${ }^{6}$ Department of Clinical Nutrition, Institute of Public Health and Clinical Nutrition, University of Eastern Finland, Kuopio, Finland

\section{*Equal contribution}

Correspondence:

Mikko Hiltunen, $\mathrm{PhD}$

Professor of Tissue and Cell Biology

Institute of Biomedicine

University of Eastern Finland

P.O. Box 1627, FI-70211 Kuopio, Finland

Tel. +358 403552014

E-mail: mikko.hiltunen@uef.fi 


\section{Abstract}

Type 2 diabetes (T2D) increases the risk of Alzheimer's disease (AD). Even though these two diseases share common molecular pathways, the mechanisms remain elusive. To shed light into these mechanisms, mice with different $\mathrm{AD}$ - and/or tauopathy-linked genetic backgrounds were utilized; APPswe/PS1dE9 (A+Tw), Tau P301L (AwT+), and APPswe/PS1dE9/Tau P301L (A+T+). Feeding these mice with typical Western diet (TWD) led to obesity and diabetic phenotype as compared to respective mice with a standard diet. TWD also exacerbated memory and learning impairment in $\mathrm{A}+\mathrm{Tw}$ and $\mathrm{AwT}+$, but not in $\mathrm{A}+\mathrm{T}+$ mice. Furthermore, RNA sequencing of mouse hippocampal samples revealed altered responses to AD-related pathologies in $\mathrm{A}+\mathrm{Tw}$ and $\mathrm{A}+\mathrm{T}+$ mice upon TWD, pointing specifically towards aberrant microglial functionality and PI3K-Akt signaling. Accordingly, fewer microglia alongside an increased number of dystrophic neurites around $\beta$-amyloid plaques, and impaired PI3K-Akt signaling, were discovered in the hippocampus of TWD mice. Mechanistic elucidation revealed that disruption of the PI3K-Akt signaling pathway by pharmacological or genetic approaches significantly decreased the phagocytic uptake and proinflammatory response as well as increased the activity of Syk-kinase upon ligand-induced activation of Trem2/Dap12 signaling in mouse microglia. Finally, characterization of microglial pathology in cortical biopsies of idiopathic normal pressure hydrocephalus (iNPH) patients harboring $\beta$-amyloid plaques revealed a significant decrease in the number of microglia per $\beta$ amyloid plaque in obese iNPH patients with T2D as compared to both normal weight and obese iNPH patients without T2D. Collectively, these results suggest that the peripheral diabetic phenotype in mice and humans associates with reduced microglial response to $\beta$-amyloid pathology.

Keywords: Alzheimer's disease, dystrophic neurites, microglia, PI3K-Akt signaling, type 2 diabetes, typical Western diet 


\section{Introduction}

Alzheimer's disease (AD) is the most common neurodegenerative disease. Typical AD pathology includes accumulation of neuritic plaques composed of $\beta$-amyloid peptide $(A \beta)$ aggregates, and dystrophic neurites positive for hyperphosphorylated Tau in the form of neurofibrillary tangles (NFTs) [6, 64]. Furthermore, activation of microglia, loss of synapses, and neuronal death are typically observed in $\mathrm{AD}$ [28]. Currently, available $\mathrm{AD}$ medication offers only a minor symptomatic relief, without any effects on the underlying pathogenic processes. Although AD has a strong genetic background, environmental and lifestyle factors, such as type 2 diabetes (T2D), play important roles in conferring the risk for AD [31]. T2D is characterized by insulin resistance in peripheral tissues, leading to increased serum insulin and glucose levels. Interestingly, AD and T2D share common features, such as impaired insulin signaling, increased levels of pro-inflammatory cytokines, metabolic changes, increased oxidative stress, and mitochondrial dysfunction [16]. However, the exact common underlying mechanisms between these two diseases remain elusive. Continuously increasing prevalence of both $\mathrm{AD}$ and $\mathrm{T} 2 \mathrm{D}$ world-wide warrants for a better mechanistic understanding of the contribution of T2D on AD risk.

Lifestyle factors, such as lack of exercise and typical Western diet (TWD) containing high fat, high sugar, high cholesterol, and low fiber play a crucial role in the development of T2D. Likewise, epidemiological studies have revealed that the consumption of saturated fats, T2D, and obesity in midlife increase the risk of $\mathrm{AD}$ later in life [14, 21, 31, 45, 50, 103]. In mice, high-fat diet (HFD) and TWD lead to obesity, glucose intolerance and finally to full-blown T2D [101]. In most of the studies, HFD and TWD have led to impaired memory in both wild-type (WT) and AD transgenic mice $[24,26,47,81]$. Also, impaired insulin-Akt signaling in the brain of HFD/TWD animals has been often reported $[34,48,73]$. However, effects of HFD/TWD on $\beta$-amyloid and Tau pathology have been controversial [22, 24, 26, 36, 99].

In the brain, insulin plays a role as a neurotrophic factor and has also been linked to neuroinflammation, while neuronal glucose intake is mainly independent of the insulin-regulated GLUT-4 transporter $[12,108]$. When insulin binds to insulin receptor (IR), it can activate two distinct branches of insulin signaling pathway: the Ras-mitogen-activated protein kinase (MAPK) and phosphoinositide 3-kinase (PI3K)-Akt-kinase pathways [41]. Akt-kinase controls the activity of GSK3 $\beta$. Reduced levels of GSK3 $\beta$ phosphorylation, specifically at the inhibitory S9 residue, in turn, result in augmented Tau phosphorylation [30]. Importantly, Akt-signaling also controls autophagic activity through mammalian target of Rapamycin complex 1 (mTORC1). Impaired autophagy is a common feature in $\mathrm{AD}$ and other neurodegenerative diseases [89]. Activation of 
PI3K-Akt-mTORC1 pathway by insulin or other stimuli inhibits autophagy, while nutrient starvation inactivates this pathway, and thus increases autophagic activity [25].

Inflammation is one of the key elements shared in both AD and T2D. Increased levels of proinflammatory cytokines, including tumor necrosis factor $\alpha(\mathrm{TNF} \alpha)$, are observed in adipose tissue of both obese and diabetic subjects as well as in the brain of AD patients [88, 93]. Recent genetic and functional studies have highlighted the relevance of the brain's innate immune cells in contributing to the onset and progression of $\operatorname{AD}[69,87]$. Specifically, studies have exemplified the emergence of reactive microglia subtypes in response to disease and damage, for which triggering receptor expressed on myeloid cells 2 (Trem2) has been identified as a central receptor [40, 49]. Transition of microglia from homeostatic to a disease-associated microglia (DAM) phenotype is a two-step process, in which Trem2-PI3K-Akt pathway plays a central role [40]. Furthermore, the deficits of Trem2 impair Akt-mTOR signaling in microglia, affecting autophagy and decreasing the ability of microglia to form a protective barrier around $\beta$-amyloid-plaques, which eventually leads to increased formation of dystrophic neurites [95].

Here, we have studied the interaction between dietary (TWD) and genetic factors (APPswe/PS1dE9 and Tau P301L mutations) and their effects on memory, brain pathology, and global gene expression in female mice with WT (AwTw) and different AD- and tauopathy-linked genetic backgrounds: Tau-P301L (AwT+), APPswe/PS1dE9 (A+Tw), and triple transgenic APPswe/PS1dE9/Tau-P301L (A+T+). To our knowledge, this is the first time when all these mouse lines have been utilized in parallel in the same study to dissect the alterations in cellular pathways in the brain associated with TWD and different AD-associated pathologies. Our results suggest that TWD exacerbates age-related memory impairment in mice with a genetic predisposition to develop AD-like brain pathology as well as alters microglial gene expression and functionality. Supporting these findings, T2D also decreased the number of $\beta$-amyloid plaque-associated microglia also in frontal cortical biopsies of living idiopathic normal pressure hydrocephalus (iNPH) patients.

\section{Materials and Methods}

\section{Animals}

In this study, we used three transgenic mouse lines with $\mathrm{C} 57 \mathrm{Bl} / 6 \mathrm{~J}$ background as models for $\mathrm{AD}$ and WT littermates with the same $\mathrm{C} 57 \mathrm{Bl} / 6 \mathrm{~J}$ background as controls. The first mouse line coexpressed in a single transgene a chimeric mouse/human APP695 harboring the Swedish K670M/N671L mutations (Mo/Hu APPswe) and human PS1 with the exon-9 deletion (PS1dE9) under mouse PrP promoter [32]. The second mouse line carried human P301L tau mutation under 
CaMKII promoter [43]. The third line was created by crossing heterozygous line 1 and 2 mice resulting in APPswe/PS1dE9 x P301Ltau mice. The study comprised of 46 female mice, 11 WT (AwTw), 13 APPswe/PS1dE9 transgenic (A+Tw), 11 tau P301L transgenic (AwT+) and 11 transgenic for both APPswe/PS1dE9 and tau P301L (A+T+). The dietary intervention started at the age of 7 months, so that half of the mice in each genotype group received a chow mimicking TWD (Adjusted Calories diet, TD 88137, Harlan Tecklad, Madison, WI, USA, with 21\% w/w fat, $0.15 \%$ cholesterol and 35\% sucrose) while the other half continued with standard rodent diet (STD) (5\% w/w fat and $0 \%$ cholesterol) until sacrificed at the age of 13 months. The mice were weighed monthly. The mice were kept in a controlled environment (constant temperature, $22 \pm 1{ }^{\circ} \mathrm{C}$, humidity $50-60 \%$, lights on 07:00-19:00), with food and water available ad libitum. All animal procedures were carried out in accordance with the guidelines of the European Community Council Directives 86/609/EEC and approved by the Animal Experiment Board of Finland.

\section{Glucose tolerance test (GTT)}

GTT for mice was done at the age of 11 months. After $3 \mathrm{~h}$ of fasting in the morning, an i.p. injection of $1 \mathrm{mg} / \mathrm{g}$ D-glucose in a $20 \%$ solution (prepared in normal saline) was given. Blood samples for the determination of glucose levels $(50-75 \mu \mathrm{l})$ were collected at time points 0 (before glucose injection) and $30 \mathrm{~min}$ after the injection from the saphenous vein. The glucose values were determined immediately using a glucometer (One Touch, LifeScan Inc., Milpitas, CA, USA).

\section{Spontaneous activity}

Spontaneous explorative activity was assessed by using an automated activity monitor (TruScan, Coulbourn Instruments, Whitehall,PA, USA) based on infrared photobeam detection. The system consisted of an observation cage with white plastic walls $(26 \mathrm{~cm}$ x $26 \mathrm{~cm}$ x $39 \mathrm{~cm}$ ) and two frames of photo detectors enabling separate monitoring of horizontal (XY-move time) and vertical activity (rearing). The test cage was cleaned with $70 \%$ ethanol before each mouse to avoid odor traces. The following parameters were measured during a 10-min session: ambulatory distance (gross horizontal locomotion) and rearing time.

\section{Morris swim navigation test}

Spatial learning and memory were assessed in the Morris swim task. The test was conducted in a white circular wading pool (diameter $120 \mathrm{~cm}$ ) with a transparent submerged platform (diameter 14 $\mathrm{x} 14 \mathrm{~cm}) 1.0 \mathrm{~cm}$ below the surface serving for escape from the water. The pool was open to 
landmarks in the room (white screen blocking the view to the computer and the experimenter, green water hose, door, 1-m high black pattern on the wall). Temperature of the water was kept at $20 \pm$ $0.5^{\circ} \mathrm{C}$. The acquisition phase was preceded by two practice days with a guiding alley to the platform (day -4 and day -3, not shown). During the acquisition phase (days 1-5), the location of the hidden platform was kept constant (SE quadrant) and the starting position varied between four different locations at the pool edge, with all mice starting from the same position in a given trial. Each mouse was placed in the water with its nose pointing towards the pool wall. If the mouse failed to find the escape platform within $60 \mathrm{~s}$, it was placed on the platform for $10 \mathrm{~s}$ by the experimenter (the same time was allowed for mice that found the platform). The acquisition phase consisted of five daily trials with a 10 min inter-trial-interval. On day 5, the search bias was tested in a 60 -s probe trial (the 5th trial) without the platform. The experimenter was blind to the genotype and treatment of the mice. The mouse was video-tracked, and the video analysis program calculated the escape latency, swimming speed, path length and time in the pool periphery $(10 \mathrm{~cm}$ from the wall) and in the platform zone (diameter $30 \mathrm{~cm}$ ).

\section{Passive avoidance test}

This task was used as a control for long-term memory, since in contrast to Morris swim task, increased activity level leads to impaired performance in this task. The mouse was placed in the well-lit side of a two-compartment box and was freely allowed to enter the dark, closed compartment through a hole in the dividing wall. As soon as the mouse entered the dark side, the slide door separating the compartment was closed and a mild foot-shock delivered $(2 \times 2$ s at 0.30 $\mathrm{mA}$ ). The mouse was then taken to its home cage. The memory for the aversive experience was assessed $48 \mathrm{~h}$ later by taking the time for the mouse to enter the dark compartment with a cut-off time of $180 \mathrm{~s}$.

\section{Tissue sampling and preparation}

At the end of the study, all mice were deeply anesthetized with intraperitoneal pentobarbituratechloralhydrate cocktail (60 mg/kg each) and transcardially perfused with ice-cold saline for $3 \mathrm{~min}$ to rinse blood from the brain. The brain was removed and placed on ice. For half of the mice, one brain hemisphere was immersion fixed in $4 \%$ paraformaldehyde, followed by $30 \%$ sucrose overnight and stored in antifreeze at $-20^{\circ} \mathrm{C}$. The other hemisphere was dissected on ice into following blocks: frontal, parieto-occipital and temporo-occipital cortices, hippocampus, cerebellum and olfactory bulb. In addition, two lobes of liver, pancreas, gastrocnemius and tibialis anterior muscles and samples of inguinal and subcutaneous fat were dissected and snap frozen in 
liquid nitrogen. The samples were stored at $-80^{\circ} \mathrm{C}$. The PFA $4 \%$ fixed hemispheres were cut using a freezing slide microtome into $35 \mu \mathrm{m}$ coronal sections. The hippocampal tissue samples were collected into microcentrifuge tubes and weighed. Samples were homogenized in $250 \mu 1$ of phosphate-buffered saline (DPBS, Lonza, Walkersville, MD, USA) using a stirrer. Fractions of homogenates were taken to RNA isolation $(50 \mu \mathrm{l}$ of homogenate and $500 \mu \mathrm{l}$ Tri Reagent (SigmaAldrich, St. Louis, MO, USA) and Western blot analysis (100 $\mu$ l of homogenate was supplemented with EDTA-free protease inhibitor cocktail (ThermoScientific, Waltham, MA, USA) and HALT'M phosphatase inhibitor cocktail (ThermoScientific, Waltham, MA, USA) 1:100. The remaining 100 $\mu 1$ of homogenate was left unprocessed and stored at $-80^{\circ} \mathrm{C}$.

\section{Histochemistry}

Snap frozen liver blocks (originally designed for biochemistry) were cut with a cryostat into $5 \mu \mathrm{m}$ sections and stained with hematoxylin-eosin to reveal lipid vacuoles indicating a fatty liver change. Despite the freezing artefact, the vacuoles were clearly visible in most cases. Three sections of each mouse were analyzed by two researchers blinded to the genotype and treatment of the mice and scored as follows: $0=$ no change, 1 = possible change, 2 = clear fatty-liver change. The brain hemispheres fixed in $4 \%$ paraformaldehyde were cut using a freezing slide microtome into $35 \mu \mathrm{m}$ coronal sections. Three brain sections, $105 \mu \mathrm{m}$ apart were selected between bregma $-3.1 \mathrm{~mm}$ and $3.5 \mathrm{~mm}$ coronal planes according to the Paxinos and Franklin atlas [71]. IHC staining was done with fluorescent secondary antibodies for free-floating sections. First, the sections were pre-treated in $0.05 \mathrm{M}$ citrate solution for $30 \mathrm{~min}(\mathrm{pH} \mathrm{6.0)}$ at $80 \square$. Endogenous peroxidase activity on sections was inhibited by incubation with $0.3 \%$ or $2 \%$ hydrogen peroxide in methanol. Non-specific antibody binding was blocked with $3 \%$ bovine serum albumin or $10 \%$ normal goat serum. To visualize $\beta$-amyloid burden and dystrophic neurites, the sections were stained with rabbit polyclonal anti-Pan-A $\beta$ (1:2000, A $\beta$ 1-40, Invitrogen, Carlbad, CA, USA) and mouse monoclonal antihuman phospho-Tau (S202, T205) AT8 (1:1000, Thermo Fisher Scientific, MN1020, UK) for dystrophic neurites. To see details of microglia around $\beta$-amyloid plaques, sections were stained with two sets of antibodies. $\beta$-amyloid plaques were stained with X-34 (SML1954, Sigma-Aldrich, St. Louis, MO, USA), microglia with rabbit polyclonal anti-Iba-1 (1:5000, \#019-19741, FUJIFILM Wako Chemicals Europe GmbH, Neuss, Germany) and lysosomes with rat monoclonal anti-Cd68 (clone FA-11, \#MCA1957, Bio-Rad, Hercules, CA, USA). In the second set, p85 was stained with mouse monoclonal anti-p85 (1:1000, Antibodies-online GmbH, Aachen, Germany) along with Iba-1 staining. Primary antibodies were incubated overnight at $+4 \square$. For X-34 staining, the sections were incubated in X-34 solution for $1 \mathrm{~h}$ and briefly rinsed with $60 \% \square \mathrm{PBS} / 40 \% \square \mathrm{EtOH}$ solution prior to 
primary antibody incubation. The sections were incubated with appropriate fluorescent secondary antibodies: goat anti-mouse 488 (Invitrogen Alexa Fluor 488, A11029, Molecular Probes, Invitrogen, Eugene, OR, USA) for p85 and AT8, goat anti-rabbit 594 (Invitrogen Alexa Fluor 594, A11037, Molecular Probes, Invitrogen, Eugene, OR, USA) for Iba-1 and Pan-A $\beta$, and goat ant-rat 488 (Invitrogen Alexa Fluor 488, A1106, Molecular Probes, Invitrogen, Eugene, OR, USA) for Cd68. The sections were mounted with Vectashield Hard Set with or without DAPI (Vector Laboratories, Burlingame, CA, USA) on gelatin-coated slides. Control sections without the primary antibodies were processed simultaneously, and no unspecific staining was observed.

\section{Fluorescent microscopy and image analysis}

The analysis of $\beta$-amyloid plaques and surrounding dystrophic neurites was done in the dentate gyrus (DG) and lateral entorhinal cortex (LEC) (Fig. 1I). Images were taken with a fluorescent microscope (Zeiss Axio Imager M2 microscope, Germany, with AxioCam ERc5s -camera attached). Both brain areas were imaged with $5 \mathrm{x}$ or $20 \mathrm{x}$ objectives. Brain areas were imaged with Zstack imaging method, 12 layers with a total distance of $15 \mu \mathrm{m}$. Dystrophic neurite counting was done with direct microscopy. The ZEN 2012 software Blue edition (Carl Zeiss Microimaging $\mathrm{GmbH}$ ) was used for image processing. The $\beta$-amyloid plaque burden was determined with Adobe Photoshop CS6 extended (version 13.0x32). To estimate the total $\beta$-amyloid burden in the studied brain regions, we measured the total area of $\beta$-amyloid plaques with the most representative threshold, same for all animals, within the defined ROI (LEC and HC) in three brain sections and divided the area by the ROI area. Thus, the $\beta$-amyloid burden was expressed as an average percentage from three brain sections. All plaques over $9.9 \mu \mathrm{m}$ diameter in both brain areas, LEC and $\mathrm{HC}$, were counted as well as dystrophic neurites around each plaque. Counting was done by an investigator blinded to the genetic and dietary background of mice.

\section{Confocal microscopy and image analysis}

Details of microglia around $\beta$-amyloid plaques were analyzed from fluorescent images of the molecular layer of dentate gyrus obtained with a Zeiss Axio Observer inverted microscope $(63 \times$ NA 1.4 oil objective) equipped with a Zeiss LSM 700 or Zeiss LSM 800 confocal module (Carl Zeiss Microimaging GmbH, Jena, Germany). For all analyses, at least three z-stack images ( $9 \mu \mathrm{m}$ with $0.9 \mu \mathrm{m}$ optical sections) were collected per brain section. Laser and detector settings were maintained constant for each immunostaining. All image processing and analyses were performed with Fiji software [84] using automated scripts. Maximum intensity projections were generated for each channel, and Gaussian blurring and rolling ball algorithm were applied to remove noise and 
subtract background, respectively. The stainings were segmented using Otsu threshold for X-34, and Moments threshold for Iba1, Cd68, and p85. For the analysis of Cd68 and Iba1, the outlines of a $\beta$-amyloid plaque were first determined automatically from the X-34 staining, then Cd68 and Iba1 staining area and intensity were analyzed within $30 \mu \mathrm{m}$ from the plaque outline. When analyzing $\mathrm{p} 85$, outlines of $\beta$-amyloid plaque was assessed manually due to a lack of X-34 staining, and then p85 staining area and intensity were analyzed within $30 \mu \mathrm{m}$ from the plaque outline. Imaging and analysis of the immunostainings was done by investigators blinded to the genetic or dietary background of mice.

\section{iNPH cohort for cortical brain biopsies}

Patients characterized in Table 1, were diagnosed with probable iNPH [78] and selected for CSF shunt surgery according to the previously described protocol [37] in Department of Neurosurgery Kuopio University Hospital from 2012 until 2017. Diagnostic right frontal cortical brain biopsy was taken during shunt surgery and occurrence of $\beta$-amyloid and/or phospho-Tau was evaluated by neuropathologist as described previously [58]. According to the neuropathological examination, all the individuals included in this study were $\beta$-amyloid positive but phospho-Tau (AT8) negative. All patients gave their written informed consent, prior to the surgery, for the study accepted by Ethics Committee, Hospital District of Northern Savo.

\section{Immunohistochemistry of human biopsy brain tissue}

The biopsy samples were fixed in buffered formalin overnight and subsequently embedded in paraffin. $5 \mu \mathrm{m}$ deparaffinized sections were used for IHC staining. Antigen retrieval was performed by boiling the sections in $10 \mathrm{mM}$ Tris $-1 \mathrm{mM}$ EDTA buffer, $\mathrm{pH} 9.0$, in pressure cooker for 10 minutes, followed by cooling to room temperature and incubation in $80 \%$ formic acid for 20 minutes. Endogenous peroxidase activity was quenched by incubation in $1 \% \mathrm{H}_{2} \mathrm{O}_{2}$ and unspecific antibody binding was blocked using $3 \%$ bovine serum albumin (BSA). Sections were incubated with the first primary antibody, rabbit polyclonal anti-Iba-1 (\#019-19741, 1:1500, FUJIFILM Wako Chemicals Europe $\mathrm{GmbH}$, Neuss, Germany) overnight at $4^{\circ} \mathrm{C}$, followed by visualization with biotinylated anti-rabbit secondary antibody (1:200, Vector Laboratories, Burlingame, CA, USA) and Vectastain Elite ABC Kit Peroxidase (Vector Laboratories, Burlingame, CA, USA) using 3,3'diaminobenzidine (DAB, Sigma-Aldrich, St. Louis, MO, USA) as chromogen with 1min 30sec incubation time. Staining of the second antigen started with blocking with $3 \%$ BSA and incubation with the second primary antibody, mouse monoclonal anti-A $\beta$ (anti- $\beta$-amyloid 17-24, clone 4G8, 
\#800712, 1:500, Biolegend, San Diego, CA, USA) overnight at $4^{\circ} \mathrm{C}$. Staining was visualized with biotinylated anti-mouse secondary antibody (1:200, Vector Laboratories, Burlingame, CA, USA) and Vectastain ABC-AP Kit (Vector Laboratories, Burlingame, CA, USA), and 30-minute incubation with Permanent AP Red Kit substrate/chromogen (Zytomed Systems GmbH, Berlin, Germany). Sections were counterstained with Mayer's haematoxylin and mounted with aqueous mounting medium (Aquatex, Merck, Darmstadt, Germany). Control sections without the primary antibodies were processed simultaneously, and no unspecific staining was observed.

\section{Imaging and analysis of human brain biopsy tissue}

The human biopsy brain tissue sections were imaged with Hamamatsu NanoZoomer-XR Digital slide scanner with 20x (NA 0.75) objective (Hamamatsu Photonics K.K.). Due to the small size of the biopsy specimen, all plaques with microglia within or around the plaque in the grey matter area of the specimen were included in the analysis. Size of the $\beta$-amyloid plaques was obtained by manually outlining the plaques in NDP.view2 software (Hamamatsu Photonics K.K.). Plaqueassociated microglia were manually counted, and the number of microglia within the plaque area and around the plaque area were recorded separately. Only microglia with clearly visible soma were included in the count. Counting and analysis was performed by an investigator blinded to sample identity.

\section{Cell cultures and treatments}

Immortalized mouse microglial BV2 cells were grown in RPMI-1640 medium (Sigma-Aldrich, St. Louis, MO, USA) supplemented with $10 \%$ fetal bovine serum (FBS, Gibco, Waltham, MA, USA), 2mM L-glutamine (Lonza, Basel, Switzerland) and 1\% penicillin-streptomycin (P/S: $100 \mathrm{U} / \mathrm{ml}$ penicillin and $100 \mathrm{U} / \mathrm{ml}$ streptomycin, Lonza, Basel, Switzerland) in $15 \mathrm{~cm}$ cell culture plates (Nunc, Roskilde, Denmark) as previously described [23]. To study the effects of PI3K inhibition on Syk phosphorylation, BV2 cells were scraped from confluent plate on RPMI-1640 medium without FBS to induce serum starvation. Cells were diluted to concentration 1 x $10^{6}$ cells $/ \mathrm{ml}$, and cell suspension was divided into 1,5 ml Eppendorf tubes. After $1 \mathrm{~h}, \mathrm{PI} 3 \mathrm{~K}$ inhibitor treatment with $1 \mu \mathrm{M}$ LY294002 (Life Technologies, Frederick, MD, USA) was started. After 1 h 40 min, Src-kinase inhibitor ( $2 \mu \mathrm{M}$ SU 6656, S9692 Sigma-Aldrich, St. Louis, MO, USA) was added. At 2 h time point, cells were treated with M-CSF (100ng/ml) Recombinant Human M-CSF (MacrophageColony Stimulating Factor, BioLegend cat. 574806, San Diego, CA, USA) for 5 min. Tubes were placed on ice and subsequently centrifuged at $10000 \mathrm{x}$ g for $1 \mathrm{~min}$ at $+4^{\circ} \mathrm{C}$. Supernatant was 
removed and cells were lysed with tissue protein extraction buffer (T-PER, ThermoScientific, Rockford, IL, USA) including EDTA-free protease inhibitor cocktail (ThermoScientific, Waltham, MA, USA) and HALT ${ }^{\mathrm{TM}}$ phosphatase inhibitor cocktail (ThermoScientific, Waltham, MA, USA) 1:100, and incubating on ice for 30min. The lysates were centrifuged at $16000 \mathrm{x} g$ for $10 \mathrm{~min}$ at $+4^{\circ} \mathrm{C}$, the protein lysates were collected into the new tubes and stored at $-20^{\circ} \mathrm{C}$. Effects of PI3K inhibition on Syk phosphorylation in mouse WT primary microglia was studied by plating 100000 cells in 96-well plate in Dulbecco's modified Eagle's medium (DMEM, Lonza, Verviers, Belgium) supplemented with 2mM L-glutamine (Lonza, Verviers, Belgium) and 1\% P/S (Lonza, Verviers, Belgium), but without FBS in order to induce serum starvation. After $1 \mathrm{~h}, \mathrm{PI} 3 \mathrm{~K}$ inhibitor treatment with $1 \mu$ M LY294002 (Life Technologies, Frederick, MD, USA) was started. After 2 h, cells were treated with Trem2 antibody (R\&D Systems, Minneapolis, MN, USA) with final concentration of $10 \mu \mathrm{g} / \mathrm{ml}$. After $5 \mathrm{~min}$ antibody treatment, plate was placed on ice, cells were lysed and supernatants were analyzed with phosphoSyk Alpha-LISA kit (PerkinElmer, Waltham, MA, USA) according to the kit instructions. Mouse primary microglia cultures from Akt2 knock-out (KO) (Mouse B6.129P2(Cg)-Akt2tm1.1Mbb/J, The Jackson Laboratory, Ben Harbor, Maine, USA) and C57BL/6 WT mice were prepared as previously [68]. Briefly, brains of neonatal (P0-P2) mice were dissected and meninges were removed. Brain tissue was dissociated using mechanical shearing and trypsin. Cells of two brains were plated on poly-L-lysine (Sigma-Aldrich, St. Louis, MO, USA) coated T75 culture flasks and cultured in Dulbecco's modified Eagle's medium (DMEM, Lonza, Verviers, Belgium) supplemented with 10\% FBS (Gibco, Waltham, MA, USA), 2mM L-glutamine (Lonza, Verviers, Belgium) and 1\% P/S (Lonza, Verviers, Belgium). On the next day, the cells were washed three times with PBS (DPBS, Lonza, Walkersville, MD, USA) to remove cellular debris and cultured with fresh DMEM with supplements. After 7 days, mature microglia were shaken off from the astrocytic feeding layer. Microglial cells were counted, and appropriate number of cells was plated in 96 well plates and used for assessing phagocytic activity and responses to inflammatory activation.

\section{Phagocytosis assay}

For pHrodo phagocytosis assays, BV2 cells were plated on 96-well plates (Nunc, Roskilde, Denmark) at 4,000 cells/well $16 \mathrm{~h}$ before starting the assay. Primary microglia were cultured in 96well plates at 20,000 cells/well in volume of 100 $\mu$ in DMEM culture medium with supplements described above. Cells were treated with PI3K inhibitor LY294002 (Life Technologies, Frederick, MD, USA) with different concentrations and with $5 \mu$ M Cytochalasin D (Sigma-Aldrich/Merck, St. Louis, MO, USA), inhibitor of actin polymerization, which served as negative control by blocking 
the phagocytosis. After $1 \mathrm{~h}$ pretreatment with the inhibitors, cells were treated with pHrodo Zymosan bioparticles (Essen BioScience, Ann Arbor, MI, USA) with a final amount of $5 \mu \mathrm{g} /$ well. Three to four wells were used for each treatment condition. Time-lapse videomicroscopy sequences of living cells were obtained using the IncuCyte S3 system (Essen BioScience, Ann Arbor, MI, USA) with 20x (BV2) or 10x (primary microglia) objective lense, and images from 4 fields per culture well were obtained every 15 minutes (BV2) or every 30 minutes (primary microglia) for up to 3 hours. pHrodo red fluorescent signal was used as an indicator of uptake by the lysosomal cell compartments. After 3h, nuclei of cells were stained with $1 \mu \mathrm{M}$ Vybrant DyeCycle Green (Molecular probes/ThermoFisher Scientific, Eugene, OR, USA) and imaged with IncuCyte in order to count the cells. Area $\left(\mu \mathrm{m}^{2}\right)$ of red fluorescence per image was calculated for each time point, normalized to total cell count, and plotted as a time course.

\section{Western blot analysis}

The inhibitor-supplemented total protein fractions were further diluted by taking $50 \mu 1$ of homogenate and adding $70 \mu \mathrm{l}$ of T-PER Tissue Protein Extraction Reagent (ThermoScientific, Rockford, IL, USA). After incubating for $20 \mathrm{~min}$ on ice, samples were centrifuged for $10 \mathrm{~min}$ at $16,000 \times g$ and the supernatant was transferred into a new microcentrifuge tube. Protein concentrations were measured using the Pierce BCA Protein Assay Kit (ThermoScientific, Waltham, MA, USA). Total protein lysates $(15-50 \mu \mathrm{g})$ were subjected to SDS-PAGE using NuPAGE 4-12\% Bis-Tris Midi Protein Gels (Invitrogen, Carlbad, MA, USA) and subsequently transferred to Polyvinylidene difluoride (PVDF) membranes using the iBlot 2 Dry Blotting System (Invitrogen, Carlbad, MA, USA). Unspecific antibody binding was prevented by incubating the blots in blocking solution containing 5\% non-fat milk or 5\% BSA (Sigma-Aldrich, St. Louis, MO, USA) in 1x Tris-buffered saline with $0.1 \%$ Tween 20 (TBST) for $1 \mathrm{~h}$ at RT. Proteins were detected from the blots using the following primary antibodies diluted in the appropriate ratio with 1x TBST and incubated overnight at $+4^{\circ} \mathrm{C}$ : rabbit anti-phospho-Akt1 (S473, 1:1000, \#9018, Cell Signaling Technology, Danvers, MA, USA), rabbit anti-phospho-Akt2 (S474, 1:1000, \#8599, Cell Signaling Technology, Danvers, MA, USA), rabbit anti-phospho-Akt (Thr308/309/305, 1:1000, \#13038, Cell Signaling Technology, Danvers, MA, USA), rabbit anti-Akt1 (1:1000, \#75692, Cell Signaling Technology, Danvers, MA, USA), rabbit anti-Akt2 (1:1000, \#3063, Cell Signaling Technology, Danvers, MA, USA), rabbit anti-Akt (1:1000, \#9272, Cell Signaling Technology, Danvers, MA, USA), rabbit anti-phospho-GSK3 $\beta$ (S9, 1:1000, \#9336, Cell Signaling Technology, Danvers, MA, USA), rabbit anti-GSK3 $\beta$ (1:1000, \#9315, Cell Signaling Technology, Danvers, MA, USA), custom-made mouse anti-phospho-Tau (B6, 1:1000) [17], mouse anti-4R-Tau (RD4, 1:1000, 05- 
804, Millipore), mouse anti-SQSTM1/p62 (1:1000, \#5114, Cell Signaling Technology, Danvers, MA, USA), mouse anti-LC3 (1:1000, ab51520, Abcam, Cambridge, UK), mouse anti-Caspase-3 (1:1000, \#9662, Cell Signaling Technology, Danvers, MA, USA), mouse anti-phospho-ERK (1:500, sc-7383, Santa Cruz Biotechnology, Dallas, TX, USA), rabbit anti-ERK2 (1:500, sc-154, Santa Cruz Biotechnology, Dallas, TX, USA), mouse anti-p85a (1:1000, ABIN1098111, Antibodies-online GmbH, Aachen, Germany), rabbit anti-phospho-SYK (1:1000, MA5-14918, Invitrogen, Waltham, MA, USA), rabbit anti-SYK (1:1000, \#13198, Cell Signaling Technology, Danvers, MA, USA), mouse anti- $\beta$-actin (1:1000, ab8226, Abcam, Cambridge, UK) and mouse anti-GAPDH (1:15000, ab8245, Abcam). Blots were subsequently probed with the appropriate horseradish peroxidase (HRP)-conjugated secondary antibodies, either sheep anti-mouse-HRP (1:5000, NA931V, GE Healthcare, Chicago, IL, USA) or donkey anti-rabbit-HRP (1:5000, NA934V, GE Healthcare, Chicago, IL, USA) diluted in 1x TBST and incubated for $1 \mathrm{~h}$ at room temperature. Enhanced chemiluminescence (ECL, GE Healthcare, Chicago, IL, USA) was used to detect the protein bands. Blots were imaged with the Chemidoc MP system (Bio-Rad, Hercules, CA, USA) and images were quantified using the ImageLab (Bio-Rad, Hercules, CA, USA) software.

\section{AlphaLISA assay}

Phospho-Syk level from WT mouse primary microglia cultures were determined using AlphaLISA SureFire Ultra kit (PerkinElmer, Waltham, MA, USA) according to manufacturer's instructions. Briefly, after treatments, cells were lysed in freshly prepared 1X Lysis buffer $(40 \mu 1 /$ well) and agitate on a plate shaker $(\sim 350 \mathrm{rpm})$ for 10 minutes at room temperature. $30 \mu \mathrm{l}$ of the lysate was transferred to a 96-well 1/2AreaPlate ${ }^{\mathrm{TM}}$ for assay. Acceptor Mix was added (15 $\mu 1 /$ well) and plate was sealed with Topseal-A adhesive film. Plate was incubated for 1 hour at room temperature covered with foil. Donor Mix was added to wells $(15 \mu 1 /$ well) under subdued light. Plate was sealed with Topseal-A adhesive film, covered with foil, and incubated for 1 hour at room temperature in the dark. Plate was analyzed with EnVision plate reader (PerkinElmer, Waltham, MA, USA), using standard AlphaLISA settings.

\section{ELISA and Nitric Oxide assays}

$A \beta 40$ and $A \beta 42$ levels in the mouse hippocampus homogenates were determined with monoclonal and HRP-conjugated antibody-based Human/Rat $\beta$ amyloid 40 ELISA kit (Wako, Osaka, Japan). Mouse TNF- $\alpha$ and IL-6 ELISA Ready-SET-Go! kits (Affymetrix, San Diego, CA, USA) were used for the detection of tumor necrosis factor $\alpha$ (TNF- $\alpha)$ and IL-6 in the conditioned media of WT and 
Akt2 KO mouse primary microglia cultures treated with LPS (200ng/ml, Sigma-Aldrich, St. Louis, MO, USA) and IFN $\gamma$ (20ng/ml, Sigma-Aldrich, St. Louis, MO, USA) for 24h. Nitric oxide (NO) levels were determined using the Griess Reagent Kit for Nitrite Determination (G-7921, Life Technologies, Eugene, OR, USA). All kits were used as recommended by the manufacturers.

\section{RNA sequencing}

Library preparation and sequencing was conducted in Finnish Functional Genomics Centre (FFGC), Turku Centre for Biotechnology, University of Turku and Åbo Akademi University. The quality of the total RNA samples as well as prepared libraries was ensured with Advanced Analytical Fragment Analyzer. Sample and library concentration were measured with Qubit ${ }^{\circ}$ Fluorometric Quantitation, Life Technologies. Library preparation was done according to Illumina TruSeq® Stranded mRNA Sample Preparation Guide (part \# 15031047). The 45 libraries with good quality were pooled in one pool and run in 2 lanes. The samples were sequenced using Illumina HiSeq 3000 instrument to a minimum read depth of 12 million reads per sample. Single-read sequencing with 1 x 50 bp read length was used, followed by $8+8$ bp dual index run.

\section{Quality control and transcript abundance quantification}

FastQC version 0.11 .8 (http://www.bioinformatics.babraham.ac.uk/projects/fastqc/) was used to examine the quality of the RNA sequencing reads. Illumina sequencing adapter sequences were removed, and reads were quality trimmed using the Trimmomatic version 0.38 [7]. The obtained trimmed reads were then mapped against the ribosomal and mitochondrial reference sequences (build mm10) using the Bowtie 2 version 2.2.3 [52]. Successfully mapped reads were abandoned. The rest of the reads were subjected to pseudo alignment to mouse reference transcriptome (build mm10) and transcript abundance quantification using kallisto version 0.44.0 [8].

\section{Differential expression analysis}

Transcript abundance estimates were collapsed to gene-level counts using $\mathrm{R}$ package tximport version 1.10.1 [90]. Gene-level counts were pre-filtered (mean of gene count > 10), normalized and variance stabilizing transformed using $\mathrm{R}$ package DESeq2 version 1.22.2 [56]. Potentially confounding batch effects were corrected using removeBatchEffect function from limma version 3.38.3 [79]. The differentially expressed genes between diet and genotype groups were analyzed using the DESeq2. 


\section{Consensus weighted gene co-expression network analysis}

We carried out Consensus Weighted Gene Co-expression Network Analysis (WGCNA) as described previously [51]. Since the experimental design contains two variables of interest (genotype and diet), we carried out a consensus network analysis of two datasets: data from AwTw, AwT+, A+Tw, and A+T+ mice on STD, and data from the same genotypes with TWD. The rationale is that a consensus analysis identifies modules that group together genes correlated in both datasets, i.e., both with respect to diet as well as genotype. A thresholding power of 6 was chosen as it was the smallest threshold that resulted in a scale-free $\mathrm{R}^{2}$ fit of 0.8 ). The "signed hybrid" network was used (deepSplit=4, minModulesize=40) in which negatively correlated genes are considered unconnected. This analysis identified 28 co-expression modules ranging from 52 to 2728 genes per module (Supplementary Table 1). Genes in each module were further represented by a single representative expression profile (module eigengene, $1^{\text {st }}$ principal component of the module). Module eigengenes were correlated with genotype to determine the association of co-expressed genes with genotype. Additionally, module eigengenes allow one to define a continuous measure of membership of all genes in all modules. Genes with high module membership in a module are called hub genes for the module. To perform differential analysis of the consensus module networks (STD and TWD genotype networks) we correlated and hierarchically sorted the identified module eigengenes for each network. Evaluation of module connectivity conservation was done by comparison of module sorting in their respective dendrograms.

\section{Gene set enrichment analysis}

We used the $\mathrm{R}$ anRichment (https://horvath.genetics.ucla.edu/html/CoexpressionNetwork/GeneAnnotation/) to calculate the enrichment of co-expression gene modules in a collection of reference gene sets that includes Gene Ontology terms, KEGG pathways, literature gene sets collected in the userListEnrichment R function [61], Molecular Signatures Database gene sets [92], aging gene sets from Enrichr [11], microglia-relevant gene sets from several recent articles $[10,18,19,40,49,100]$ and other gene sets. Fisher's exact test was used to evaluate overlap significance.

\section{Transcription factor enrichment analysis}

Over-represented transcription factor binding motifs (TFBS) and potential transcription factors (TF) in the surroundings of the transcription start site (TSS) of the differentially expressed genes (adjusted p-value <0.005 due to diet) were identified using R package RcisTarget version 1.4.0 [1]. 
We used genome wide TFBS ranking database containing regions from 500bp_upstream_and_100bp_downstream from TSS (motif collection mc9nr / mm10). Identified significantly enriched TFBS (normalized enrichment score (NES) threshold > 4.0) were annotated to TFs by using provided annotation database.

\section{Cell type enrichment analysis}

Cell type enrichment was determined by cross-referencing of module genes with lists of genes known to be preferentially expressed in different cell types in mouse brain [86, 107]. All identified genes were used as background. Significance of enrichment of cell type markers with clusters was assessed using one tailed Fisher's exact test.

\section{Statistics}

IBM SPSS version 25 and $\mathrm{R}$ were used to analyze the data. Kolmogorov-Smirnov test was used first to test the normality of the distributions. The body weight at 12 months of age, blood glucose levels in the glucose tolerance test, spontaneous activity, latency to enter on day 2 in passive avoidance and search bias in the Morris swim task were analyzed with two-way ANOVA with A genotype, $\mathrm{T}$ genotype, and diet as between-subject factors. The task acquisition across days in Morris swim task was assessed with a mixed ANOVA for repeated measures (ANOVA-RM) using day as the within-subject and $\mathrm{A}$ and $\mathrm{T}$ genotypes as between-subject factors. $\beta$-Amyloid plaque load and the number of dystrophic neurites around plaques were analyzed separately for LEC and HC among A+ transgenic mice with two-way ANOVA using the $\mathrm{T}$ genotype and diet as factors. Statistical comparisons of biochemical analysis results were performed using two-way ANOVA followed by Fisher's Least Significant Difference (LSD) post-hoc test. Statistical comparisons of correlations were performed using Spearman's rho test. Results are expressed as mean \pm standard error of mean (SEM) of control samples. P-values $<0.05$ were considered statistically significant.

\section{Results}

\section{Feeding of mice with TWD results in T2D}

At the beginning of the dietary intervention, mice in the different test groups weighed on average between 22.5 - $24.4 \mathrm{~g}$. There was no difference between APPswe/PS1dE9 genotypes (Aw vs. A+, p $=0.32$ ), or Tau P301L genotypes (Tw vs. $\mathrm{T}+, \mathrm{p}=0.57$ ) but mice in the to-be STD groups tended to 
weigh more than mice in the to-be TWD groups, $\mathrm{p}=0.04)$. During the 6-month dietary intervention, there was a significant diet effect on the body weight increase $\left(F_{6,33}=25.6, p<0.001\right)$, while the weight gain was less robust in A+ mice on TWD as compared to Aw mice $(\mathrm{p}=0.01)$ (Fig. 1a). In the GTT, baseline glucose levels were higher $\left(F_{1,38}=3.8, p=0.06\right.$; Fig. $\left.1 \mathrm{~b}\right)$ and 30 min glucose levels robustly elevated $\left(\mathrm{F}_{1,38}=13.9, \mathrm{p}=0.001\right.$; Fig. $\left.1 \mathrm{c}\right)$ in TWD groups as compared to STD groups. A possible fatty liver change was assessed in hematoxylin-eosin stained liver sections and blindly scored by two raters. Evidence of lipid vacuoles was found in 20/24 mice (69\%) fed with TWD, but only in 5/22 mice (23\%) fed with STD. Additionally, clear fatty liver changes were found in 12/24 TWD mice (50\%), and in none of the STD mice (Fig. 1d). The diet effect was highly significant on the fatty liver score $(\mathrm{p}<0.001$, Mann-Whitney), while neither $\mathrm{A}(\mathrm{p}=0.32)$ nor $\mathrm{T}(\mathrm{p}=$ 0.19) genotype influenced the score. In summary, feeding the mice with TWD results in a phenotype related to T2D irrespective of genotype.

\section{TWD exacerbates memory impairment associated with $\beta$-amyloid pathology}

Previous studies have demonstrated that transgenic mice overexpressing the APPswe/PS1dE9 mutation are hyperactive $[39,80]$. Here, A+ mice traversed a significantly longer distance during the 10-min test time than Aw mice $\left(\mathrm{F}_{1,38}=15.7, \mathrm{p}<0.001\right)$, whereas the T genotype $(\mathrm{p}=0.43)$ or diet $(\mathrm{p}=0.84)$ did not influence spontaneous locomotion (Fig. 1e). Thus, to rule out the possible confounding effect of hyperactivity associated with the A+ genotype, we chose spatial navigation, where hyperactivity may speed up learning, and passive avoidance, where hyperactivity is unfavorable for the outcome, as tests for assessing possible memory impairment. In passive avoidance, all three factors (diet, $\mathrm{A}+$, and $\mathrm{T}+$ genotypes) showed a significant effect on the latency to enter the punished dark compartment, $48 \mathrm{~h}$ after the learning episode. A+ mice performed worse as compared to Aw mice $\left(\mathrm{F}_{1,38}=8.8, \mathrm{p}=0.005\right)$, $\mathrm{T}+$ mice worse than Tw mice $(\mathrm{p}=0.02)$ and TWD mice worse as compared to STD mice $(p=0.02)$ (Fig. 1f). In the acquisition phase of Morris swim navigation task, there was no difference between the groups in their swimming speed (for all main effects $\mathrm{p}>0.60)$. A+ mice had significantly longer escape latencies than Aw mice $\left(\mathrm{F}_{1,38}=11.6, \mathrm{p}=\right.$ 0.002), whereas the $\mathrm{T}$ genotype $(\mathrm{p}=0.27)$ and diet $(\mathrm{p}=0.46)$ did not influence escape latencies (Fig. 1g). In the probe test on day 5 for search bias, A+ mice spent less time in the former platform zone than Aw mice $\left(\mathrm{F}_{1,38}=12.6, \mathrm{p}=0.001\right)$ while the $\mathrm{T}$ genotype did not affect the search bias $(\mathrm{p}=$ 0.64). TWD tended to further impair the search bias in the groups with mixed genotypes (AwT+ or A+Tw; Fig. 1h), but overall, the diet main effect was not significant ( $p=0.10)$. Altogether, this suggests that TWD exacerbates memory impairment in mice associated with $\beta$-amyloid pathology. 
TWD-induced T2D does not influence $\beta$-amyloid plaque load but increases the number of neuritic plaques

An obvious question behind the exacerbation of memory impairment of A+ mice by TWD is whether the diet aggravated the brain $\beta$-amyloid pathology. This question actually has two components; first, whether the dietary intervention affects the brain $\beta$-amyloid load, and second, whether it affects the formation of dystrophic neurites around the $\beta$-amyloid plaques, i.e. formation of neuritic plaques that are the most characteristic pathological feature of AD. To this end, we analyzed $\beta$-amyloid load in A+ mice in the lateral entorhinal cortex (LEC) and dentate gyrus of hippocampus (HC) (Fig. 1i), the brain sites with the earliest pathological changes in human AD and substantial $\beta$-amyloid plaque pathology in the APPswe/PS1dE9 mouse model. One mouse in the A+Tw STD group was removed as an outlier in this analysis to obtain normal distribution of data (Fig. $1 \mathrm{j}$ and $\mathrm{k})$. Neither the $\mathrm{T}+$ genotype $\left(\mathrm{F}_{1,21}=0.4, \mathrm{p}=0.52\right)$ nor diet $(\mathrm{p}=0.17)$ significantly influenced the $\beta$-amyloid load in LEC (Fig. 1 j) or in HC (Fig. 1k, T: p = 0.50, diet: p = 0.74). Accordingly, no significant effect by $\mathrm{T}+$ genotype or diet on soluble A $\beta 42$ (Supplementary Fig. 1a, $\mathrm{T}: \mathrm{F}_{1,17}=0.006, \mathrm{p}=0.94$, diet: $\left.\mathrm{F}_{1,17}=0.60, \mathrm{p}=0.45\right), \mathrm{A} \beta 40$ (Supplementary Fig. 1b, $\mathrm{T}: \mathrm{F}_{1,17}=1.0$, $p=0.32$, diet: $F_{1,17}=3.4, p=0.08$ ), or $A \beta 42 / 40$ ratio (Supplementary Fig. $1 c, T: F_{1,17}=0.003, p=0.95$, diet: $\left.\mathrm{F}_{1,17}=0.37, \mathrm{p}=0.55\right)$ was found in hippocampal lysates of these mice. Next, we assessed the number of phospho-Tau (AT8)- positive dystrophic neurites around $\beta$-amyloid plaques (Fig. 11). To this end, we counted the number of $\beta$-amyloid plaques above the threshold diameter of $9.9 \mu \mathrm{m}$ in three LEC and three HC sections in each mouse, yielding 58-119 plaques per mouse in LEC and 47 - 84 plaques per mouse in HC. Recent evidence suggests that the number of dystrophic neurites around $\beta$-amyloid plaques in transgenic APP mice increases with the plaque diameter [5]. We found a similar relationship between the plaque diameter and the number of neurites both in LEC $\left(\mathrm{R}_{1923}=\right.$ $0.28, \mathrm{p}<0.001)$ and $\mathrm{HC}\left(\mathrm{R}_{1467}=0.36, \mathrm{p}<0.001\right)$ (data not shown). Importantly, the average plaque diameter did not differ between the diet groups either in LEC $\left(\mathrm{t}_{1921}=0.48, \mathrm{p}=0.63\right)$ or in $\mathrm{HC}\left(\mathrm{t}_{1465}\right.$ $=1.5, \mathrm{p}=0.14$ ) (data not shown). However, TWD significantly increased the number of neurites around $\beta$-amyloid plaques in both LEC $\left(\mathrm{F}_{1,1919}=80.3, \mathrm{p}<0.001\right)$ and $\mathrm{HC}\left(\mathrm{F}_{1,1463}=6.9, \mathrm{p}=0.009\right)$, while the T genotype had no effect in either LEC $(\mathrm{p}=0.11)$ or in HC $(\mathrm{p}=0.07)$ (Fig. $1 \mathrm{~m}$ and $\mathrm{n})$. Collectively, phenotypic and biochemical assessments show that TWD exacerbates memory impairment associated with $\beta$-amyloid pathology. However, TWD does not alter total $\beta$-amyloid load, $\beta$-amyloid peptide ratios or plaque diameter in mouse brain, but instead significantly increases the number of plaque-associated dystrophic neurites.

TWD suppresses global transcriptional response to AD pathology in the hippocampus 
To evaluate the impact of TWD on the AD-associated transcriptional response, we performed RNAsequencing on hippocampal samples from AwTw, AwT+, A+Tw and A+T+ mice on STD or TWD. Assessment of the primary sources of variance in the dataset by principal component analysis (PCA) revealed gradual separation between AwTw, AwT+, A+Tw, and A+T+ mice, with A+T+ showing greatest separation from AwTw mice, suggesting that the combination of $\beta$-amyloid and Tau pathologies generates the most potent pathological state (Supplementary Fig. 2b). Separate PCA for mice of each genotype (to dissect diet effects) showed defined separation between STD and TWD samples in all genotypes, suggesting an effect for TWD on the transcriptional landscape of the hippocampus upon both $\beta$-amyloid and Tau pathology, as well as in the healthy state (Supplementary Fig. 2c). Surprisingly, almost no genes were differentially expressed (DE; false discovery rate $(\mathrm{FDR})<0.05)$ in AwT+ mice on both STD (3 up, 1 down) or TWD (1 up, 0 down), when compared to respective AwTw mice (Supplementary Fig. 2d, Supplementary Table 1-2). In turn, we observed 203 DE (199 up, 4 down) genes in A+Tw/STD mice and 173 DE genes (166 up, 7 down) in A+Tw/TWD mice. In accordance with the notion that $\beta$-amyloid and Tau pathologies potentiate each other's effects, we observed 338 DE genes (294 up, 44 down) in A+T+/STD mice, but only 177 DE genes (162 up, 15 down) in A+T+/TWD mice. In general, a smaller amount of DE genes was observed in TWD mice when compared to STD mice, which was most evident in A+T+ mice. Comparison of the DE genes between STD and TWD mice for each genotype show a large overlap in genes, with unique DE genes mainly observed in STD mice (Supplementary Fig. 2d), suggesting a similar but less potent response in TWD mice when compared to STD mice. To further compare the transcriptional response between STD and TWD mice, we correlated DE analysis Zstatistic values for STD and TWD mice for each genotype. A strong positive correlation can be considered a highly similar transcriptional response. This analysis revealed only modest correlations $(\mathrm{AwT}+$, cor $=-0.309$ (data not shown); $\mathrm{A}+\mathrm{Tw}$, cor $=0.415 ; \mathrm{A}+\mathrm{T}+$, cor $=0.165$, Fig. $2 a)$, supporting the notion that TWD mice display an impaired transcriptional response to ADrelated pathologies. Next, we performed enrichment analyses of DE genes (Supplementary Table 3) using a curated collection of both public gene sets (e.g., GO and MSigDB) and self-curated gene set collections (Methods). Consistent for both $\mathrm{A}+\mathrm{Tw}$ and $\mathrm{A}+\mathrm{T}+$ mice, the top enrichment term for upregulated genes was "Top human microglia-specific genes", irrespective of diet. Interestingly, a significant enrichment for synaptic function-associated terms (e.g. "chemical synaptic transmission" $\mathrm{p}=6.7 \times 10^{-03}$ ) was only observed for genes downregulated in $\mathrm{A}+\mathrm{T}+\mathrm{TWD}$ mice. Enrichment analysis of genes showing discordant response in mice with $\mathrm{A}+$ or $\mathrm{A}+\mathrm{T}+$ background upon TWD as compared to STD mice (Fig. 2a, blue points: $Z>2.5$ or $<-2.5$ in STD, but not in TWD) indicated enrichment for microglia-specific terms (e.g. "Top human microglia-specific genes", "Genes 
correlated with Trem2"), suggesting that TWD largely alters the transcriptional response of microglia (Supplementary Table 4). Expression profiles of genes displaying a discordant response revealed that the majority of genes were either up- or downregulated already in AwTw mice, showing only minor changes in relation to $\beta$-amyloid and/or Tau pathology. This could suggest that TWD locks microglia to a type of intermediate state (Supplementary Fig. 3a). Taken together, these results suggest a large range of transcriptional changes due to TWD, which potentially alter the response of microglia and neurons to $\beta$-amyloid and/or Tau pathology as compared to STD mice.

\section{TWD diminishes $\beta$-amyloid and Tau pathology-associated microglial gene expression signatures}

To further identify AD pathology-associated molecular networks that may be selectively affected by TWD in mouse brains, we performed consensus weighted gene co-expression network analyses (WGCNA; [51]). Our consensus WGCNA analysis identified 28 co-expression modules (Supplementary Table 5; Fig. 2c). By relating the module eigengene (a representative vector for the genes in a module, see methods), [51] to genotype, we identified six modules significantly positively associated and seven modules significantly negatively associated with genotype in either STD or TWD mice (Fig. 2c). A positive association can be considered as an increase in the expression of module genes in response to $\mathrm{A}+$ and/or $\mathrm{T}+$ background, and vice versa for negative association. A weaker association for the majority of the positively and negatively related modules in TWD mice was detected (Fig. 2c). Conversely, two negatively associated modules (MEdarkturquoise, MEcyan) showed a weaker association in STD mice (Fig. 2c). Comparison of the relations between STD and TWD network modules similarly revealed a loss in network preservation upon TWD as compared to the STD network, largely for positively associated modules, especially the MEdarkred module (Supplementary Fig. 3b).

Cell type enrichment analysis of the network modules revealed a significant enrichment for neuronal and astrocytic markers for negatively regulated modules, and for microglial and endothelial cell markers in positively correlated modules (Supplementary Fig. 3c). Accordingly, modules that negatively correlated with genotype were significantly enriched for neuron-related terms (Supplementary Table 6). In turn, top positively correlated modules were significantly enriched for "Top Human Microglia-Specific Genes", and more specifically "Immune Response", "Genes Correlated with Trem2", and genes "Upregulated in AD-associated Microglia (Keren-Shaul et al., 2017)". This suggests that the top identified positively associated modules recapitulate a microglial Trem2-driven DAM response, which is partially impaired upon TWD. MEdarkred, which had a poor preservation between the STD and TWD networks, was significantly enriched in genes related to the Wnt signaling pathway. Previously, it was shown that downregulation or knock- 
out of Trem2 in microglia results in reduced Akt S473 and Gsk3 $\beta$ S9 phosphorylation, resulting in $\beta$-catenin degradation and impaired Wnt/ $\beta$-catenin [109]. These results suggest that TWD in mice potentially alters microglial functionality downstream of Trem2 signaling, thus resulting in the observed partial transcriptional response when compared to STD mice.

To assess whether any modules associated with Tau pathology, $\beta$-amyloid pathology or the combination of both, we plotted eigengene expression levels for each genotype and diet (Fig. 2e, Supplementary Fig. 3d). The most evident pathology-dependent alterations were observed in the top two positively associated modules, MEtan and MEorange, where an increase in eigengene expression was driven primarily by the presence of $\beta$-amyloid pathology. In turn, MEdarkturquoise, MEgreen, MElightyellow, MEblue, and MElightcyan, and MEred and MEpink modules showed a more linear change in expression (in order: AwTw, AwT+, A+Tw, A+T+), with the greatest decrease or increase in $\mathrm{A}+\mathrm{T}+$ mice when compared to AwTw mice. Interestingly, MEroyalblue and MEdarkred modules showed only modest or no changes in expression in AwT+ or A+Tw mice, but an increase in expression in $\mathrm{A}+\mathrm{T}+$ mice. This suggests that in some cases $\beta$-amyloid and Tau cooperate to cause specific transcriptional alterations in mouse brain, which is in line with recent findings [74]. Overall, our network analysis reveals a strong transcriptional response to $\beta$-amyloid pathology and combined $\beta$-amyloid and Tau pathologies in genes predominantly expressed in microglia and associated with microglia-specific biological terms. Specifically, a Trem2-driven DAM type profile was recapitulated, and this was partially impaired in TWD mice, potentially due to altered downstream signaling of Trem2.

TWD induces aberrant expression of disease-associated microglia signature genes in mouse hippocampus

As TWD was found to change the transcriptional landscape in mouse hippocampus in WT (AwTw) and transgenic mice $(\mathrm{AwT}+, \mathrm{A}+\mathrm{Tw}, \mathrm{A}+\mathrm{T}+)$, resulting in an altered basal state and response to $\beta$ amyloid and Tau pathology, we next concentrated on the genes that were altered by the diet irrespective of genotype to pin-point potential key TWD-associated pathways. DE analysis for TWD mice vs. STD mice revealed 4428 DE genes (2698 up, 1730 down, Fig. 2f, Supplementary Table 7), enriched for terms related to ribosomes, mitochondria (e.g. "mitochondrial protein complex"), and genes up-/downregulated in AD-/ALS-associated microglia ("Up-regulated in ADassociated microglia [40], "Upregulated in Stage2 vs. Stage1 disease-associated microglia") (Supplementary Table 8). Given that our genotype and diet DE analysis and network analysis suggested that TWD alters the previously described DAM response, we examined the overlap between TWD DE genes and DAM genes ([40], genes with FDR $<0.01$ and FC $>3$ or $<-3$ ). This 
analysis revealed an overlap of 132 genes with top DE hits, such as Pik3rl (FDR = 0.004, Log2FC $=-0.40)$, Tyrobp $(\mathrm{FDR}=0.006, \log 2 \mathrm{FC}=0.37)$, and Tmem1 $19(\mathrm{FDR}=0.008, \log 2 \mathrm{FC}=0.29)$. The expressional changes of Pik3r1, Trem2, and Tyrobp detected by RNA-sequencing were confirmed using conventional qPCR (Supplementary Fig. 4). Despite observing a general lack of transcriptional response associated with Trem2 correlated genes, we observed an increase in both Trem 2 and Tyrobp expression levels. However, the expression of Pik3rl, a gene encoding PI3K regulatory subunit 1 and directly acting downstream of Trem2, was decreased. This finding highlights Pik3rl as a potentially important candidate in conveying the observed TWD effects, given the importance of the PI3K-mediated insulin signaling in the brain, the role of the Trem2PI3K-Akt pathway in DAM activation, and the observed alterations in Trem2- and Wnt signaling pathways in our WGCNA analysis. Lastly, as TWD causes a large scale of transcriptomic effects, we sought to determine the transcription factors potentially regulating the observed top DE genes ( $\mathrm{p}<0.005)$. Enrichment for three significantly differentially expressed transcription factors, Foxol, Ep300, and Elf1 was identified (Fig. 2f).

\section{TWD leads to decreased Akt and increased Gsk3 $\beta$ activation in hippocampus}

Since analysis of the RNA-sequencing data revealed decreased expression levels of Pik3rl, the gene encoding p85 $\alpha$ subunit of PI3K, in hippocampus of mice with TWD as compared to STD, we next assessed whether there are alterations in well-known downstream targets in PI3K-Akt-Gsk3 $\beta$ Tau pathway. We analyzed hippocampal protein lysates using Western blot and found that phosphorylation of S473 in Akt1 kinase, a residue regulating Akt1 activation, was significantly decreased in TWD mice as compared to STD mice $\left(F_{1,38}=30, p<0.001\right.$, Fig. 3a). This was an expected finding, considering the decreased p85a expression. In line with this, phosphorylation of the corresponding S474 site in Akt2 $\left(\mathrm{F}_{1,38}=9.9, \mathrm{p}=0.003\right.$, Fig. $\left.3 \mathrm{~b}\right)$ and of another activating site, T308/309/305 in Akt1/2/3, respectively, $\left(\mathrm{F}_{1,38}=28.9 \mathrm{p}<0.001\right.$, Fig. 3c) were significantly decreased in the hippocampus of TWD mice as compared to STD mice. Furthermore, Akt-mediated phosphorylation of the inhibitory S9 residue in Gsk3 $\beta$, a well-characterized Tau-kinase, was significantly decreased in mice on TWD as compared to $\operatorname{STD}\left(\mathrm{F}_{1,38}=14.3, \mathrm{p}<0.001\right.$, Fig. 3d), suggesting increased Gsk3 $\beta$ activity. However, no diet effect was observed on Tau phosphorylation between the TWD and STD mice $\left(\mathrm{F}_{1,37}=0.67, \mathrm{p}=0.42\right)$, while Tau phosphorylation was significantly reduced in mice with $\mathrm{T}+$ genotype (Supplementary Fig. $1 \mathrm{~d}, \mathrm{~F}_{1,37}=48, \mathrm{p}<0.001$ ). The typical 64-kDa band [82] present above the endogenous mouse Tau bands in $\mathrm{T}+$ mice $(\mathrm{P} 301 \mathrm{~L}$ overexpressing human Tau) was included into the quantification. However, excluding the 64-kDa band from the analysis does not change the result. As expected, total Tau levels were significantly 
increased in $\mathrm{T}+$ as compared Tw mice (Supplementary Fig. 1d, $\mathrm{F}_{1,41}=141, \mathrm{p}<0.001$ ). The diet also had a significant effect on total Tau levels $\left(\mathrm{F}_{1,41}=10.8, \mathrm{p}=0.002\right)$. As previously described, hyperphosphorylated, aggregated Tau becomes insoluble, which might explain why increased Tau phosphorylation was not detected in hippocampal homogenates in this analysis. In contrast, IHC analysis showed that TWD significantly exacerbated dystrophic neurite i.e. phosphorylated Tau pathology in both $\mathrm{A}+\mathrm{Tw}$ and $\mathrm{A}+\mathrm{T}+$ mice in the vicinity of $\beta$-amyloid plaques (HC and LEC, Fig 11n).

Since energy metabolism and PI3K-Akt signaling are known to regulate autophagy, protein levels of well-known autophagy markers p62 and LC3B were next assessed in hippocampal lysates. Levels of p62 were significantly increased in TWD mice as compared to STD mice (Fig. 3e, $\mathrm{F}_{1,38}=$ 6.9, $\mathrm{p}=0.012$ ), suggesting that TWD decreases autophagy. This was unexpected, since impaired activation of PI3K-Akt pathway has been shown to lead to decreased levels of p62 [46, 105] reflecting enhanced autophagic degradation. LC3B detection revealed increased levels of cytosolic LC3BI form and no membrane-bound lipidated LC3BII form in TWD mice as compared to STD mice (Fig. 3e, $F_{1,38}=6.3$, p=0.016), further suggesting decreased autophagy.

Hippocampus is in a central role in processes related to learning and memory. Thus, we next analyzed whether the results of the behavioral tests correlated with any biochemical assessments in the hippocampal lysates. Higher body weight at age of 12 months (W12) and higher weight gain (WG) between 5 and 12 months negatively correlated with phosphorylation of Akt1 S473 (W12: $\mathrm{R}=-0.417, \mathrm{p}<0.01$ and WG: $\mathrm{R}=-0.453, \mathrm{p}<0.01$ ), Akt2 S474 (W12: $\mathrm{R}=-0.373, \mathrm{p}<0.01$ and WG: $\mathrm{R}=-$ 0.373, $\mathrm{p}<0.01)$ and Gsk3 $\beta$ S9 (W12: $\mathrm{R}=-0.292, \mathrm{p}<0.05$ and $\mathrm{WG}: \mathrm{R}=-0.331, \mathrm{p}<0.05)$. However, no correlation between peripheral glucose intolerance and Akt/Gsk3 $\beta$ phosphorylation status was found. Interestingly, mean latency time to find the hidden platform in the acquisition phase of Morris swim task revealed a strong negative correlation with phosphorylation of Akt1 S473 (R=0.355, $\mathrm{p}<0.016)$, Akt2 S474 ( $\mathrm{R}=-0286, \mathrm{p}=0.054)$, and Gsk3ß S9 $(\mathrm{R}=-0.353, \mathrm{p}<0.05)$, suggesting that the stronger the Akt/Gsk3 $\beta$ signaling, the faster the mice find the platform. However, spontaneous movement activity did not correlate with Akt or Gsk3 $\beta$ phosphorylation. Altogether, these results strongly suggest that decreased Pik3rl expression upon TWD coincides with significantly decreased activity of Akt1/2 (both S473/474 and T308/309/305 catalytic sites) and increased activity of Gsk3 $\beta$. Furthermore, TWD exacerbates dystrophic neurite pathology in both $\mathrm{A}+\mathrm{Tw}$ and $\mathrm{A}+\mathrm{T}+$ mice in the vicinity of $\beta$-amyloid plaques (HC and LEC, Fig 11-n).

TWD reduces clustering of microglia around $\beta$-amyloid plaques in mice 
Since RNA-sequencing data also suggested that TWD leads to altered Trem2-signaling and general transcriptional response of microglia, we next assessed if TWD affected microglia-related pathology around $\beta$-amyloid plaques in mouse and human IHC samples. Hippocampal sections of $\mathrm{A}+\mathrm{Tw}$ and $\mathrm{A}+\mathrm{T}+$ mice were triple-stained with anti-Iba1 (microglia), anti-Cd68 (lysosomal marker expressed in activated microglia) and X-34 ( $\beta$-amyloid plaque) to assess microglia clustering and lysosomal activity around plaques. Iba1-positive area within $30 \mu \mathrm{m}$ from the plaque was found to decrease in TWD as compared to STD mice (Fig. 4a-b, diet $\mathrm{p}<0.05$ ). No diet effect on Cd68positive area was observed. However, significant reduction of both Iba1 and Cd68 intensities were detected in mice fed with TWD as compared to mice fed with STD (Fig. 4c, diet p<0.001), suggesting that the number of microglia and lysosomal activity around plaques is reduced. Also, $\mathrm{T}+$ genotype, on top of the A+ background, significantly increased both Ibal and Cd68 intensity (Fig. $4 \mathrm{c}, \mathrm{p}<0.001$ ), suggesting that Tau pathology further potentiates microglia activation in $\mathrm{A}+$ mice.

Next, we wanted to assess whether the decrease of $\mathrm{p} 85 \alpha$ expression observed at the transcriptional level could also be detected specifically in microglia around $\beta$-amyloid plaques in IHC samples. Hippocampal sections of mice with $\mathrm{A}+\mathrm{Tw}$ and $\mathrm{A}+\mathrm{T}+$ genotypes were triple stained with anti-Iba1, anti-p85 $\alpha$ and DAPI to assess p85 $\alpha$ in microglial cells. Plaque-associated microglia were identified by the typical clustering pattern of Iba1 immunopositive microglia around the $\beta$ amyloid plaques (Fig. 4a and 4d). The analysis revealed a significant genotype $\mathrm{x}$ diet interaction on both $\mathrm{p} 85 \alpha$ area and intensity (Fig. $4 \mathrm{e}$, genotype $\mathrm{x}$ diet, $\mathrm{F}_{1,247}=15.2$, $\mathrm{p}<0.001$ ). In A+Tw mice, TWD increased the levels of $\mathrm{p} 85 \alpha$ in microglia surrounding the $\beta$-amyloid plaques. The $\mathrm{T}+$ genotype also increased $\mathrm{p} 85 \alpha$ levels in the microglia around $\beta$-amyloid plaques (Fig. $4 \mathrm{e}, \mathrm{T}+$ genotype, $\mathrm{F}_{1,247}=$ 15.9, $\mathrm{p}<0.001$ for $\mathrm{p} 85 \alpha$ area and $\mathrm{F}_{1,247}=7.2, \mathrm{p}=0.008$ for $\mathrm{p} 85 \alpha$ intensity) However, in contrast to $\mathrm{A}+\mathrm{Tw}$ on TWD and A+T+ mice on STD, TWD induced a significant reduction in the levels of p85 in plaque-associated microglia in $\mathrm{A}+\mathrm{T}+$ mice. In conclusion, these data indicate that TWD reduces clustering of microglia around the $\beta$-amyloid plaques in $\mathrm{A}+\mathrm{Tw}$ and $\mathrm{A}+\mathrm{T}+$ mice, which could be linked to the altered expression of $\mathrm{p} 85 \alpha$ in the microglia.

Metabolic phenotype affects microglia clustering around $\beta$-amyloid plaques in probable iNPH patients with $\beta$-amyloid pathology

To assess the effect of the metabolic phenotype on microglia in humans, we analyzed the extent of microglia clustering around $\beta$-amyloid plaques (Fig. 4f) in frontal cortical biopsies obtained from living patients with probable iNPH (Table 1). Subjects were divided in to three groups: normal weight individuals $(\mathrm{BMI}<25)$, obese individuals $(\mathrm{BMI}>30)$, and obese individuals with $\mathrm{T} 2 \mathrm{D}$ diagnosis $(\mathrm{BMI}>30+\mathrm{T} 2 \mathrm{D})$. In accordance with our findings in TWD-fed mice, we observed a 
statistically significant decrease in the number of microglia around $\beta$-amyloid plaques in obese individuals with T2D as compared to both normal weight and obese individuals without T2D, when assessing microglia both around and within the plaque area $(\mathrm{p}<0.001)$ (Fig. $4 \mathrm{~g}$ ) as well as microglia only within the plaque area $(\mathrm{p}<0.001)$ (Fig. 4h). Interestingly, no difference was observed in the number of microglia between $\mathrm{BMI}<25$ and $\mathrm{BMI}>30$ groups. Thus, our results indicate that $\mathrm{T} 2 \mathrm{D}$, not obesity, reduces microglia clustering around $\beta$-amyloid plaques in the frontal cortical biopsies of probable iNPH patients.

Modulation of PI3K-Akt signaling pathway affects phagocytosis and proinflammatory response in mouse microglia

Since TWD exacerbated dystrophic neurite pathology, reduced the clustering of microglia around $\beta$ amyloid plaques, and decreased the expression of Pik3rl in the hippocampus of A+Tw and A+T+ mice as compared to STD mice with the same genetic backgrounds, we next examined the microglia-specific molecular mechanisms underlying these observations. PI3K is a heterodimeric enzyme composed of the catalytic p110 subunit and the regulatory p85 subunit, which catalyzes the phosphorylation of $\mathrm{PI}(4,5) \mathrm{P}_{2}$ to the lipid second messenger $\mathrm{PI}(3,4,5) \mathrm{P}_{3}$ [41]. Pik3r1 is abundantly expressed in mouse microglia [107] and it encodes three regulatory isoforms of PI3K (p85 $\alpha, \mathrm{p} 55 \alpha$ and $\mathrm{p} 50 \alpha$ ), which are produced through alternative splicing [29]. To modulate PI3K-Akt signaling and to model the subsequent effects of decreased Pik3rl expression in mouse BV2 and neonatal primary microglia upon basal and LPS-induced stress conditions, we used the well-established PI3K inhibitor LY294002 and studied the effects on autophagosomal activity (the ratio of LC3BII/I), mitogen-activated protein kinase kinase (Mek)/extracellular signal-regulated kinase (Erk) pathway, apoptosis, and phagocytic uptake (Fig. 5a-f). The treatment of BV2 cells with LY294002 showed an expected dose-dependent decrease in the phosphorylation status of S473 in Akt (pAkt) in both normal and LPS-induced stress conditions (Fig. 5a and b), reflecting decreased Akt activity. LPS treatment alone significantly increased the levels of pAkt in BV2 cells as compared to untreated cells, which is consistent with our previous results [60]. In parallel with the reduced activity of Akt, the ratio of the autophagosomal marker LC3BII/I was increased in a dosedependent manner as expected, particularly in the BV2 cells treated with both LPS and LY294002 (Fig. 5a-d and Supplementary Fig. 5). Conversely, the phosphorylation status of Erk1 and 2 (pErk1 and 2) in the activating Y204 site decreased in a dose-dependent manner in LY294002 samples, while the levels of active caspase- 3 and p $85 \alpha$ were unchanged in the BV2 cells treated with both LPS and LY294002 (Supplementary Fig. 5). 
Next, live cell imaging of BV2 and primary microglia treated with LY294002 revealed a dose-dependent decrease in the phagocytic uptake of pHrodo-labeled bioparticles (Fig. 5e and f). Moreover, primary microglia isolated from neonatal Akt2 knock-out (Akt2 KO) mice also showed a significant decrease in the phagocytic uptake of pHrodo-labeled bioparticles as compared to WT microglia (Fig. 5f). The treatment of Akt2 KO microglia with LY294002 further decreased the phagocytic uptake of bioparticles as compared to untreated Akt2 KO microglia. Akt2 KO microglia cultures showed reduced levels of secreted Tnf- $\alpha$, Il6 and nitric oxide (NO) in the culture medium as compared to the WT microglia cultures in response to LPS treatment (Fig. 5g). Altogether, these results suggest that the inhibition of PI3K-Akt signaling by using pharmacological (LY294002) or genetic (Akt2 KO mouse model) approaches significantly decreases the phagocytic uptake affects the autophagic and Erk kinase activity, and dampens the production of proinflammatory cytokines and NO upon LPS-induced stress in mouse microglia.

Ligand-induced activation of Trem2/Dap12 upon the inhibition of PI3K-Akt signaling enhances the activation of spleen tyrosine kinase in mouse microglia

PI3K plays a central role in the Trem2/Dap12-mediated signaling in mouse macrophages and osteoclasts upon ligand-induced activation, resulting in alterations in Erk kinase activity, mobilization of calcium, reorganization of actin, and apoptosis [72]. Importantly, the same study showed that inhibition of PI3K prevented recruitment of $\mathrm{p} 85 \alpha$ and spleen tyrosine kinase (Syk kinase) to Dap12. This is an intriguing finding given the fact that upon ligand binding to Trem2, the tyrosine residues within ITAM domain of Dap12 are phosphorylated, which leads to the recruitment of Syk kinase to activate downstream signaling molecules, such as PI3K, Erk, and phospholipase $\mathrm{C} \gamma 2$ (Plc 2 2) [72]. To assess whether inhibition of PI3K exerts a similar effects also in microglia, the phosphorylation of Dap12 and Syk kinase (Y525/526, pSyk) by Src-kinase was stimulated by using macrophage colony stimulating factor (M-CSF) in mouse BV2 microglia with or without LY294002 (Fig. 6a-c). M-CSF is known to activate Dap12 and Syk kinase through outside-in signaling within minutes after the treatment $[72,110]$. The treatment of BV2 cells with M-CSF for five minutes resulted in the expected $\sim$ two-fold increase in pSyk levels $(p<0.001)$ as compared to control cells, which was abolished by Src-kinase inhibitor SU665 as shown previously [110](Fig. 6a and c). Unexpectedly, the combined treatment with LY294002 and M-CSF significantly increased the levels of pSyk in BV2 cells $(\mathrm{p}<0.05$, Fig. 6a-c). To further pinpoint the observed inhibitory effect of PI3K on pSyk levels in the Trem2/Dap12 signaling pathway, we used Trem2 antibody for direct ligand-induced activation of Trem2 alone or in combination with LY294002 for five minutes (Fig. 6d). Alpha-LISA-based analysis of pSyk showed an average 2.5-fold increase in the levels of 
pSyk after the treatment of primary microglia cultures with Trem2 antibody as compared to control cultures (Fig. 6d). Similar to the combined treatment with LY294002 and M-CSF in the BV2 cells, co-treatment of primary microglia with LY294002 and Trem2 antibody significantly further potentiated the increased levels of pSyk. These results suggest that the inhibition of PI3K activity increases Syk kinase activity upon ligand-induced activation of Trem2/Dap12 signaling in the microglia.

\section{Discussion}

TWD, which is manifested as increased intake of energy-dense foods high in saturated fat, sugar and cholesterol, and low in fiber, is a major contributor to the increasing prevalence of obesity and T2D, imposing a global health challenge. Several studies have shown that TWD, obesity, and T2D increase the risk of $\operatorname{AD}[14,21,31,45,50,103]$. Despite these seminal studies, the underlying molecular mechanisms remain elusive. Here, we have assessed the effects of six-month TWD exposure on memory, brain pathology, and global gene expression in female mice with different genetic backgrounds linked to AD and/or tauopathy (A+Tw, AwT+ and A+T+). In addition, we set the goal to address the translation of the mouse model-derived results to humans by utilizing cortical biopsies obtained from living iNPH patients presenting with $\beta$-amyloid pathology. In this unique human tissue sample set [53], we were able to specifically address T2D- and obesity-related effects in the frontal cortex of normal weight and obese iNPH patients with or without T2D. To our knowledge, this is the first study, which comprehensively addresses the full spectrum of ADassociated pathologies in parallel in several transgenic mouse lines and human cortical tissue samples with $\beta$-amyloid pathology to elucidate TWD-, T2D, and obesity-related alterations in cellular processes.

We successfully induced obesity and diabetic phenotype in all of the mouse lines used by applying a six-month TWD regime, starting at the age of seven months, which is in line with previous reports [26, 36, 73, 94]. Furthermore, TWD strongly increased fatty liver changes, emphasizing the robust effect of TWD on the metabolism of not only in the brain but also in peripheral tissues, as also shown previously [97]. Our results related to the behavioral assessments strongly suggest that TWD-induced obesity and diabetic phenotype impair memory and learning, which are also supported by the previous findings [24, 26, 33, 34, 38, 47, 81]. More specifically, the comparison of the four genotypes suggests that adverse effects of TWD on memory and learning 
are the most prominent in mice with a moderate genetic predisposition to develop AD-like brain pathology $(\mathrm{A}+\mathrm{Tw}$ and $\mathrm{AwT}+)$, while in the $\mathrm{A}+\mathrm{T}+$ mice, the strong genetic burden overpowers the effect of TWD. Previous studies have shown that TWD and HFD associate with increased risk of developing $\mathrm{AD}[57,65]$, and cause more severe $\mathrm{AD}$-associated neuropathological changes in various mouse models $[66,67]$. Here, we observed a significantly increased number of phosphoTau (AT8)-positive dystrophic neurites around $\beta$-amyloid plaques in both lateral entorhinal cortex and hippocampus in mice with $\mathrm{A}+$ and $\mathrm{A}+\mathrm{T}+$ genotypes upon TWD. Some studies have reported that HFD or TWD does not have an effect on dystrophic neurites nor Tau pathology in APPswe/PS1dE9 or Tau P301L mice, respectively [20, 22]. However, in an opposite experimental setup, Buccarello et al. showed fewer AT8-positive cells in the cortex and hippocampus of Tau P301L mice fed with low-fat and low-protein diet as compared to STD [9], suggesting that diet can modulate the dystrophic neurite pathology. In the present study, TWD or T+ genotype did not affect $\beta$-amyloid pathology in the lateral entorhinal cortex or hippocampus of mice with A+ genotype. This was not surprising, since we have shown previously that $\beta$-amyloid burden does not correlate with memory impairment in APPswe/PS1dE9 mice [62]. Furthermore, several studies have reported adverse effects of HFD on memory and learning without exacerbating $\beta$-amyloid pathology in $\mathrm{AD}$ mouse models $[47,73,83]$. Conversely, other studies have suggested that HFD increases cortical $\beta$ amyloid load in APPswe/PS1dE9 [15] and 3xTgAD mice [36]. To our knowledge, our study is the first that demonstrates an increased number of phospho-Tau (AT8)-positive dystrophic neurites around $\beta$-amyloid plaques in AD mouse models upon TWD. This is an important finding since dystrophic neurites are a hallmark of dense-core neuritic plaques, which are used in the neuropathological diagnosis of $\mathrm{AD}$ owing to their association with cognitive impairment [85].

Studies investigating diet-associated molecular mechanisms in APP23 transgenic mice have shown that HFD increases the expression of genes associated with immune response and inflammation, such as Trem2, Tyrobp, P2ry12, Dock2 as well as a number of cytokines, chemokines and toll-like receptors [67]. Here, we observed a significant increase in the expression of Trem2 and Tyrobp and other well-established DAM signature genes [40], likewise suggesting an increased immune response in $\mathrm{A}+\mathrm{Tw}$ and $\mathrm{A}+\mathrm{T}+$ mice upon STD. However, it should also be emphasized that $\mathrm{A}+\mathrm{Tw}$ and $\mathrm{A}+\mathrm{T}+$ mice upon STD did not differ in relation to DAM response. Further analysis of the transcriptomic alterations revealed a partially suppressive effect of TWD related to immune response in mice with $\mathrm{A}+$ or $\mathrm{A}+\mathrm{T}+$ genotypes. Detailed examination indicated that the genes affected by TWD correlated with Trem2 expression and were also intimately associated with the DAM signature [40]. This suggests that TWD suppresses the microglial response to $\beta$-amyloid pathology and that this repressive response is linked to Trem2-related 
processes, such as DAM activation. This molecular reprogramming of microglia upon TWD was further supported by the decreased Iba1 and Cd68 positivity around $\beta$-amyloid plaques in TWD mice. Thus, both expressional and IHC analyses independently support the idea of a repressed immune response to TWD, which is eventually manifested as decreased number of microglia and increased number of dystrophic neurites around the $\beta$-amyloid plaques. Moreover, the decreased intensity of the lysosomal Cd68 may suggest that the functional capacity of the remaining microglia around the $\beta$-amyloid plaques is compromised.

Evaluation of the effects of TWD irrespective of the genotype also revealed a substantial overlap with altered expression of the previously described DAM genes. Pik3rl, encoding for p $85 \alpha$, was one of the top hits in the DE analysis. Since Pik3rl was downregulated in the hippocampus by TWD irrespective of the genotype, we asked whether any key PI3K-Akt signaling pathway components were affected by TWD. Indeed, a decreased phosphorylation of Akt1/2 at the S473/S474 and T305/308/308 activation sites as well as at the inhibitory S9 site of Gsk3 $\beta$ were observed in the hippocampus of TWD mice. Our findings are in line with previous studies showing that the PI3K-Akt-Gsk3 $\beta$ signaling pathway is impaired in mouse and rat brain upon HFD and TWD $[33,73]$. Interestingly, previous analyses in human post-mortem samples have demonstrated decreased levels of $\mathrm{p} 85 \alpha$ in the brain of $\mathrm{AD}$ patients [63] as well as in AD patients with co-morbid T2D [55]. Importantly, Liu et al. showed that the decrease in the levels of phosphorylated and total p $85 \alpha$ was more prominent in the brain of these comorbid patients as compared to AD patients without $\mathrm{T} 2 \mathrm{D}$, and that the alterations in $\mathrm{p} 85 \alpha$ coincided with altered phosphorylation of the downstream targets AKT and GSK3 $\beta$ [55]. Also, previous studies in different mouse models with a diabetic or obese phenotype have detected decreased levels of $\mathrm{p} 85 \alpha$ in the brain tissue [27]. Conversely, caloric restriction in $\mathrm{Tg} 2576$ mice led to increased protein levels of $\mathrm{p} 85 \alpha$ in the cerebral cortex as compared to control mice alongside with increased activity of Akt1 [77]. In general, GSK3 $\beta$ is one of the main kinases phosphorylating Tau in the brain [30]. Thus, decreased phosphorylation of the inhibitory S9 site in Gsk3 $\beta$ upon TWD may explain the increased number of AT8-positive dystrophic neurites observed in our study. Supporting this idea, increased phosphorylation of Tau due to HFD or TWD in mice and rats has been observed also previously [4, $33,73]$. On the other hand, our biochemical analysis did not reveal clear changes in the levels of phosphorylated or total Tau by the TWD, which might be due to limited solubility of aggregated Tau protein with the extraction method used. In fact, there are also other studies, in which the effects of HFD or TWD on the phosphorylation status of Tau has not been conclusive in the biochemical assessments [36, 47, 81, 83]. 
Alterations of PI3K-Akt signaling are known to affect multiple cellular functions, such as autophagy, metabolism, proliferation, cell survival, and growth [44]. Here, we found increased levels of the autophagy markers p62 and LC3BI in the hippocampal total protein lysates of TWD mice, suggesting decreased autophagosomal activity. Given the decreased activation of Akt-kinase due to TWD, this was an unexpected finding since the activated Akt-kinase is known to activate mTORC1, which again inhibits the induction of autophagy [102]. However, our observation related to the increased p62 levels is consistent with previous studies reporting increased p62 levels in the peripheral tissues, hypothalamus, and hippocampus of mice on HFD [13, 75, 104]. Furthermore, HFD has been linked to impaired lysosomal activity [104]. These findings suggest that also other pathways in addition to PI3K-Akt signaling pathway control autophagy. Indeed, 5' AMP-activated protein kinase (AMPK) is a conserved sensor of nutritional status, which may affect autophagy independently of mTORC1 [42]. Since starvation is a well-known inducer of autophagy, the opposite condition with high energy supply, such as TWD, may result in reduced autophagy.

The fact that Pik3rl is abundantly expressed in mouse microglia [107] together with our RNAsequencing data prompted us to elucidate mouse microglial functions upon downregulation of PI3K-Akt signaling by both pharmacological and genetic approaches. Inhibition of PI3K-Akt signaling using LY294002 both in mouse BV2 and primary microglia significantly decreased the phagocytic uptake of bioparticles in a dose-dependent manner. A similar decrease was observed in the primary microglia isolated from Akt2 $\mathrm{KO}$ mice. Interestingly, the treatment of Akt $2 \mathrm{KO}$ microglia with LY294002 further reduced the phagocytic uptake of bioparticles, suggesting that PI3K-Akt pathway as a whole entity plays a key role in the regulation of phagocytic activity in microglia. LPS treatment of Akt2 KO microglia cultures reduced the levels of the inflammatory mediators Tnf- $\alpha$, Il6 and NO in the culture medium, which agrees with the previous findings indicating that Akt2 $\mathrm{KO}$ macrophages are hyporesponsive to LPS [2]. Apart from being the regulatory subunit of $\mathrm{PI} 3 \mathrm{~K}, \mathrm{p} 85 \alpha$ encompasses a significant role in controlling the actin organization and cell migration, independently of PI3K activity [35]. Therefore, it is possible that the reduction in the expression of Pik3rl owing to TWD does not only affect PI3K activity, but also other functions that are relevant for microglia. On the other hand, studies in Pik3rl knock-out mice have revealed that the lack of p85 $\alpha$ subunit reduced the activity of PI3K and Akt in the peritoneal exudate cells upon LPS-induced stress [59]. Moreover, the LPS treatment of Pik3rl knock-out mouse cells induced the expression of Tnf and Il 6 as well as increased the nuclear localization of phosphorylated transcription factor ATF-2, known to increase proinflammatory cytokine expression in LPS-stimulated monocytes [59]. In conclusion, modulation of the activity of PI3K-Akt signaling pathway affects central functions of microglia, such as phagocytic uptake, autophagosomal 
degradation, and proinflammatory response against different stressors, including $\beta$-amyloid. In this context, TWD-associated reduction in the expression of Pik3rl encoding p85a may significantly contribute to the observed suppressive immune response and reduced clustering of microglia around the $\beta$-amyloid plaques. On the other hand, the results from the IHC analysis of $\mathrm{p} 85 \alpha$ were partially conflicting, since the area and intensity of $\mathrm{p} 85 \alpha$ around $\beta$-amyloid plaques was increased upon TWD in $\mathrm{A}+\mathrm{Tw}$ mice, while in $\mathrm{A}+\mathrm{T}+$ mice, the effect was the opposite. However, this type of genotype dependency is also observed in the RNA-sequencing data, where the most aberrant effects on transcriptional response were observed in $\mathrm{A}+\mathrm{T}+$ mice.

Several studies have reported that HFD affects particularly microglial phenotype, function and/or inflammatory outcomes $[3,20,98]$. Trem 2 has been shown to play a central role in AD and one of its functions is to act as a lipid-sensing receptor affecting microglial response [100]. In addition to microglia and cells of myeloid origin (e.g. monocytes, macrophages and osteoclasts), Trem2 is also expressed in mature adipocytes [70], and has been shown to affect insulin resistance in HFD mice through adipose tissue remodeling [54]. These reports emphasize that alterations in Trem2 signaling may also mediate the effects of HFD or TWD. Related to this, we now show that the ligand-induced activation of Trem2/Dap12 both directly (Trem2 antibody) and indirectly (MCSF) upon the inhibition of PI3K-Akt signaling enhanced the activation of Syk kinase in mouse microglia. This was an unexpected result since it has been previously shown that the inhibition of PI3K in macrophages and osteoclasts prevented the recruitment of p85 $\alpha$ and Syk kinase to Dap12, leading to reduced downstream signaling via other mediators, such as Plc 2 [72]. Whether the observed increase in Syk kinase activation is a compensatory effect for the reduced downstream signaling in microglia remains to be determined in future studies. Collectively, these results highlight the seminal role of $\mathrm{p} 85 \alpha / \mathrm{PI} 3 \mathrm{~K}$ in the activation of Trem2/Dap12 signaling pathway, particularly in the formation and activation of Syk kinase complex in microglia. Recent studies suggest that impaired Trem2-Akt-mTOR signaling in AD patients carrying TREM2 risk variants and in Trem2-deficient mice with AD-like microglia affects autophagy and metabolism [95] and decreases the ability of microglia to form a protective barrier around $\beta$-amyloid plaques, leading to axonal dystrophy [106]. The findings of the present study, including the increased number of dystrophic neurites and impaired PI3K-Akt signaling, large range of transcriptional changes in the microglial genes due to TWD and/or A+ genotype, and decreased Iba1 and Cd68 immunoreactivity around $\beta$-amyloid plaques similarly to previous studies, suggest that indeed impaired PI3K-Akt signaling reduces microglia clustering and their ability to form a protective barrier around plaques $[95,106]$. Consequently, this may lead to leakage of toxic $\beta$-amyloid aggregates disturbing neuronal integrity. Our observation that TWD increased the number of AT8-positive dystrophic neurites 
around the $\beta$-amyloid plaques supports this hypothesis. RNA-sequencing did not reveal major alterations in the expression of Gfap, suggesting that TWD does not affect astrocyte reactivity.

In order to elucidate whether similar alterations to those observed in microglia in the TWD mice could also be detected in human brain tissue, we utilized frontal cortical brain biopsies obtained from iNPH patients harboring $\beta$-amyloid pathology. Brain biopsies taken during shunt surgery offer a unique window into the brain tissue of living iNPH patients to examine the early stages of AD-related brain pathology [53]. We found that the combination of obesity and T2D led to presence of fewer microglia around the $\beta$-amyloid plaques compared to normal weight and obese iNPH patients without T2D, which is well in concordance with our findings in mice with the TWDinduced diabetic phenotype. Neuropathological examination revealed no Tau pathology (AT8 immunoreactivity) in the cortical tissue samples from the iNPH patients with respect to normal weight, obese, or diabetic phenotype, suggesting that $\beta$-amyloid drives the microglial alterations in the brain of these patients. Altered microglial response to $\beta$-amyloid plaques due to T2D has been suggested earlier, although no quantitative data have been presented [96]. Interestingly, increased microglial dystrophy has been reported in the hypothalamus of obese individuals [3] as well as in the hippocampus and several cortical areas in $\mathrm{AD}$ patients [76, 91]. Collectively, our results together with previous studies in both mouse and human support the idea that obesity and T2D contribute to microglial dysfunction. According to our present data, particularly T2D-related metabolic changes appear disturb microglial function around $\beta$-amyloid plaques. We have focused here on the most prominent effects of TWD in mice with different AD- and/or tauopathy-associated genetic backgrounds. However, the identified novel targets and regulatory networks associated with the individual genotypes (AwT,$+ \mathrm{A}+\mathrm{Tw}$, and $\mathrm{A}+\mathrm{T}+$ ) will set the basis for further elucidation of the underlying mechanisms related to the comorbidity of AD and T2D. Moreover, the fact that similar results were obtained in the brain tissue of TWD mice and iNPH patients with T2D lays an outstanding foundation to test novel therapeutic interventions, focusing specifically on the microglial response and clustering, against $\mathrm{AD}$-associated pathologies in the brain.

\section{Acknowledgements}

This study was supported by Academy of Finland (grant numbers 288659, 307866, 315459); Sigrid Jusélius Foundation; the Strategic Neuroscience Funding of the University of Eastern Finland; JPco-fuND2 Personalised Medicine for Neurodegenerative Diseases (grant number 334802); Doctoral Programme in Molecular Medicine (DPMM) at the University of Eastern Finland; European Union Horizon 2020 research and innovation programme (grant number 692340);Finnish Functional Genomics Centre, University of Turku and Åbo Akademi; and Biocenter Finland. Part 
of the work was carried out with the support of UEF Cell and Tissue Imaging Unit, University of Eastern Finland, Finland. The computational analyses were performed on servers provided by UEF Bioinformatics Center, University of Eastern Finland, Finland.

\section{Figure Legends}

Fig. 1 TWD leads to T2D, memory impairment and increased number of dystrophic neurites in mice with AD-linked genetic backgrounds. a Weight of mice at age of 12 months (Two-way ANOVA). b Glucose tolerance test (GTT) results after $3 \mathrm{~h}$ fasting (Two-way ANOVA). c Serum glucose levels in GTT after $30 \mathrm{~min}$ of D-glucose injection ( $\mathrm{p}=0.001$, Two-way ANOVA). d Representative liver sample image of TWD. Mice with TWD had significantly higher fatty liver score as compared to mice with STD ( $<<0.001$, Mann-Whitney). Black arrows indicate lipid vacuoles. Scale bar $20 \mu \mathrm{m}$. e Assessment of spontaneous activity ( $\mathrm{p}<0.001$, Two-way ANOVA). $\mathbf{f}$ Passive avoidance test revealed impaired performance of mice with TWD as compared to mice with STD (diet effect, $\mathrm{p}=0.02$, Two-way ANOVA). Also AD and tauopathy-associated transgenes impaired the performance (APPswe/PS1dE9; $<<0.001$ and Tau; $p<0.001$, Two-way ANOVA). Three outliers were left out from statistical analysis (in brackets) $\mathbf{g}$ In five-day learning phase of Morris swim navigation test, mice with APPswe/PS1dE9 transgene (red lines) did not learn to find the platform as fast as mice without APPswe/PS1dE9 transgene (blue lines, p=0.002, Two-way ANOVA), while TWD and Tau transgene did not affect learning. h On day five, mice with APPswe/PS1dE9 transgene spent significantly less time in platform zone ( $\mathrm{p}=0.001$, Two-way ANOVA). Also, mice with TWD spent less time in platform zone as compared to mice with STD, but the difference did not reach statistical significance $(\mathrm{p}<0.09$, Two-way ANOVA). i A representative image of APPswe/PS1dE9 mouse coronal brain section used for assessing $\beta$-amyloid plaque load from lateral entorhinal cortex (LEC) and from dentate gyrus (DG) of hippocampus 
(HC). $\mathbf{j}$ Amyloid burden quantification in LEC, and $\mathbf{k}$ in HC. $\mathbf{l}$ A representative fluorescence microscope image of APPswe/PS1dE9 mouse coronal brain section showing AT8-positive dystrophic neurites around $\beta$-amyloid plaques. $\mathbf{m}$ Quantification of neurites/plaque in LEC showing significant increase in TWD mice as compared to STD mice $(\mathrm{p}<0.001)$. n Also, in HC number of neurites per plaque was increased in TWD mice as compared to STD mice $(p=0.009)$. All results are shown as mean + SEM, behavioral tests: $n=5-7$ mice/group, Two-way ANOVA, immunohistochemistry: $n=5-6$ mice/group, 3 brain slices/mouse. Dystrophic neurites around $\beta$ amyloid plaques (diameter $>10 \mu \mathrm{M}$ ) were counted, Kruskal-Wallis H-test.

\section{Fig. 2 Transcriptomic and co-expression network analysis reveal impaired microglial response to} AD-related pathology. a Transcriptome-wide response comparison of STD and TWD mice to A+ and A+T+ background. Plots show Z-statistics derived from DE analysis for A+Tw/STD vs. AwTw/STD (x-axis) and A+Tw/TWD vs. AwTw/TWD (y-axis) (left) and A+T+/STD vs. AwTw/STD (x-axis) and A+T+/TWD vs. AwTw/TWD (y-axis) (right). Points (genes) showing concordant response in STD and TWD cases are indicated in red, and discordant response for TWD as compared to STD, in blue. Genome-wide correlations of Z statistics and the corresponding correlation values are indicated on the top of each panel. b Enrichment analysis of genes showing discordant response to A+ or A+T+ background in TWD mice as compared to STD mice (blue dots in A). Enrichment ratio = number of observed divided by the number of expected genes. $\mathbf{c}$ WGCNA modules significantly associated to genotype in either STD or TWD mice. The color and value in the box represent correlation coefficient value. The value in parentheses represents corresponding correlation p-value. d Enrichment analysis for WGCNA module genes. Color indicates FDR value and size enrichment ratio. e Box plots representing eigengene values for modules positively associated with genotype. Points represent eigengene values for each mouse in that group. Box plots show the median, 25th and 75th percentiles, error bars show 1.5 interquartile ranges. $\mathbf{Z} Z$-score value heatmap of DE genes for STD vs. TWD mice with FDR $<0.005$ and enriched transcription factors (TFs) with FDR < 0.05. n=4-6 mice/group.

Fig. 3 TWD induces impaired Akt-Gsk3 $\beta$ signaling in the brain. a Western blot analysis of hippocampal lysates showing decreased phosphorylation of S473 in Akt1 in mice with TWD as compared to STD $(\mathrm{p}<0.001)$. Diet had no effect on total Akt1 levels. b Similarly, phosphorylation of S474 in Akt2 is decreased in mice with TWD as compared to STD ( $p<0.01)$. Diet had a minor, but statistically significant effect on total Akt2 levels $(\mathrm{p}<0.05)$. c Also, phosphorylation of T308/309/305 residue in Akt1/2/3, respectively, was significantly decreased in mice with TWD as compared to STD $(\mathrm{p}<0.001)$. Total Akt1/2/3 levels showed no significant changes. d 
Phosphorylation of Gsk3 $\beta$ at the inhibitory S9 residue was significantly decreased in mice with TWD as compared to mice with STD $(\mathrm{p}<0.01)$. A+ genotype increased slightly, but significantly Gsk3 $\beta$ S9 phosphorylation $(\mathrm{p}<0.05)$ as well as total Gsk3 $\beta$ levels $(\mathrm{p}<0.05)$. e A representative Western blot image and quantification of hippocampal lysates showing increased levels of the autophagy markers p62 and LC3B in TWD mice as compared to STD mice $(\mathrm{p}<0.05)$. Phosphorylated protein levels were normalized to their respective total protein levels in cell lysates and total protein levels were normalized to Gapdh or $\beta$-actin. All results are shown as mean + SEM, $\mathrm{n}=5-7$ mice/group, Two-way ANOVA.

Fig. 4 TWD and T2D alter microglial response to $\beta$-amyloid plaques in AD mice and human brain biopsies. a Representative immunofluorescence images of $\beta$-amyloid plaques stained with X34 (blue) surrounded by Iba1 positive microglia (red) and lysosomes stained with Cd68 (green)

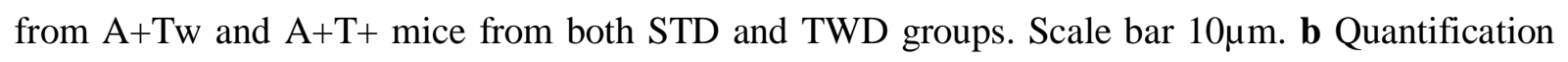
revealed that TWD significantly $(\mathrm{p}<0.05)$ decreased Iba1 positive area (pixels) as compared to STD in both $\mathrm{A}+\mathrm{Tw}$ and $\mathrm{A}+\mathrm{T}+$ mice, while diet showed no effect on Cd68 positive area. c Also, intensity of both Iba1 and Cd68 (arbitrary units) was significantly decreased ( $p<0.001$, both) in mice with TWD as compared to STD in both genotypes. Furthermore, $\mathrm{T}+$ genotype significantly increased both Iba1 and Cd68 intensity ( $<<0.001$, both). d Representative immunofluorescence images of Iba1 positive microglia (red) and p85 $\alpha$ staining (green) around $\beta$-amyloid plaques in hippocampus of A+T+ mice from both STD and TWD groups. Scale bar 10 $\mu \mathrm{m}$. e Quantification of p85 $\alpha$ revealed statistically significant genotype $\mathrm{x}$ diet interaction $(\mathrm{p}<0.001)$ in both $\mathrm{p} 85 \alpha$ area and $\mathrm{p} 85 \alpha$ intensity. $\mathrm{T}+$ genotype significantly increased both $\mathrm{p} 85 \alpha$ area $(\mathrm{p}<0.001)$ and $\mathrm{p} 85 \alpha$ intensity $(\mathrm{p}=0.007)$, while diet had opposing effects on p85 $\alpha$ depending on the genotype. A-E; results are shown as mean + SEM, n=5-6 mice/group, Two-Way ANOVA. f Representative image of frontal cortex biopsy sample from probable iNPH subject co-stained for IBA1 (brown) and $\beta$-amyloid (red). White arrows denote microglia within the plaque area, and black arrow denotes microglia around the plaque area. Scale bar $10 \mu \mathrm{m}$. g Quantification of IBA1-positive microglia within and around the $\beta$ amyloid plaque. $\mathbf{h}$ Quantification of IBA1-positive microglia within the plaque area. $\mathbf{g}$-h; results are shown as mean $\pm \mathrm{SEM}, \mathrm{n}=3-5$ subjects/group

Fig. 5 Modulation of PI3K-Akt pathway affects autophagic and phagocytic activity as well as inflammatory response in microglial cells. a A representative Western blot image of lysates of BV2 cells treated with LY294002 (LY) $(0.1 \mu \mathrm{M}-10 \mu \mathrm{M})$, and b with LY294002 together with LPS. c Quantification revealed that LY294002 decreased Akt S473 phosphorylation levels dosedependently in cells treated with LY294002 and together with LPS and LY294002. d 
Quantification of LC3B II and I levels revealed a significant increase in LCB3II/I ratio by LY294002. e Phagocytic activity in BV2 cells was assessed using pHrodo bioparticles and fluorescence emission was measured in the IncuCyte live cell imaging device in every $15 \mathrm{~min}$. BV2 cells were treated with four different concentrations of PI3K inhibitor LY294002 $(5 \mu \mathrm{M}-50 \mu \mathrm{M})$ and with $5 \mu \mathrm{M}$ Cytochalasin D (CytD). LY294002 decreased phagocytic activity dose-dependently $(\mathrm{p}<0.001)$ and CytD blocked phagocytosis almost completely. a-d; Data are presented as mean + SEM from four biological replicates. Mann-Whitney U-test, ${ }^{*} \mathrm{p}<0.05, * * \mathrm{p}<0.01, * * * \mathrm{p}<0.001$ vs. untreated control, $\# \mathrm{p}<0.05, \# \# \mathrm{p}<0.01, \# \# \# \mathrm{p}<0.001$ vs. LPS control. f Phagocytic activity of primary microglia isolated from WT and Akt2 KO mice was assessed similarly as in BV2 cells using pHrodo bioparticles and fluorescence emission was measured in the IncuCyte live cell imaging device in every $30 \mathrm{~min}$. Cells were treated with three different concentrations of LY294002 $(1 \mu \mathrm{M}-$ $25 \mu \mathrm{M}$ ) and with $5 \mu \mathrm{M}$ CytD. LY294002 decreased phagocytic activity dose-dependently ( $<<0.001)$ and Akt 2 KO cells showed significantly decreased phagocytic activity as compared to WT cells $(\mathrm{p}<0.001)$. CytD blocked phagocytosis almost completely in both WT and Akt2 KO cells. e-f; Data are presented as mean + SEM from three biological replicates in technical quadruplets, One-way ANOVA, LSD (e) and Two-way ANOVA (f) g Levels of inflammatory markers, nitric oxide (NO), tumor necrosis factor $\alpha(\operatorname{Tnf} \alpha)$, and interleukin 6 (Il6) were significantly lower in Akt2 KO primary microglia as compared to WT primary microglia after $48 \mathrm{~h}$ LPS+IFN $\gamma$-treatment. Data presented as mean $\%+$ SEM, n=3-4. *p<0.05, **p<0.01, T-test.

Fig. 6 Inhibition of PI3K activity affects phosphorylation of Syk in microglial cells. a Western blot analysis of lysates of BV2 cells pre-treated with LY294002 (LY, 1 $\mu$ M) or Src-kinase inhibitor SU6656 (SU, $2 \mu \mathrm{M}$ ) prior to M-CSF treatment. b Quantification of Akt S473 phosphorylation levels revealed a significant decrease in LY294002-treated samples while total Akt levels were unchanged. c Quantification of Syk (Y525/526) phosphorylation levels revealed a significant increase in LY294002-treated samples while total Syk levels were unchanged. d Phosphorylation status of Syk was significantly increased in WT primary microglia treated with Trem2 antibody for 5 min as compared to control cells (ST). LY294002 treatment together with Trem2 antibody further increased phosphorylation. ST; starvation only, M-CSF; 100ng/ml for $5 \mathrm{~min}, \mathrm{LY} ; 1 \mu \mathrm{M}$ LY294002 for $1 \mathrm{~h}$ before M-CSF, SU; $2 \mu \mathrm{M}$ Src-kinase inhibitor SU6656 treatment $20 \mathrm{~min}$ before M-CSF. Data presented as mean $\%+$ SEM, $n=3, * \mathrm{p}<0.05, * * \mathrm{p}<0.01, * * * \mathrm{p}<0.001$, One-way ANOVA, LSD 
Table 1. Demographics, clinical status, and pathology of iNPH cases

\begin{tabular}{|c|c|c|c|c|c|c|c|c|c|c|}
\hline Group & Gender & $\begin{array}{c}\text { Age } \\
\text { (years) }\end{array}$ & $\begin{array}{c}\text { Weight } \\
\text { (kg) }\end{array}$ & $\begin{array}{c}\text { Height } \\
\text { (cm) }\end{array}$ & $\mathrm{BMI}^{(1}$ & $\begin{array}{c}\text { HOMA- } \\
\text { IR }^{(2}\end{array}$ & $\mathbf{T} 2 \mathbf{D}^{(3}$ & $\begin{array}{l}\text { Hyper- } \\
\text { tension }\end{array}$ & $\begin{array}{c}\mathrm{A} \beta \\
\text { pathology }\end{array}$ & $\begin{array}{c}A P O E \\
\text { genotype }\end{array}$ \\
\hline \multirow{5}{*}{ BMI $<25$} & Female & 67 & 70 & 170 & 24.2 & 0.6 & no & no & positive & 34 \\
\hline & Male & 79 & 65 & 168 & 23 & 2.7 & no & no & positive & 34 \\
\hline & Male & 75 & 56 & 159 & 22.2 & 0.7 & no & yes & positive & 44 \\
\hline & Female & 71 & 60 & 158 & 24 & 1.9 & no & no & positive & 33 \\
\hline & avg. & 73 & 63 & 164 & 23.4 & 1.5 & & & & \\
\hline \multirow{4}{*}{ BMI $>30$} & Female & 71 & 87 & 160 & 34 & 4.9 & no & no & positive & 34 \\
\hline & Male & 81 & 102 & 171 & 34.9 & 7 & no & no & positive & 33 \\
\hline & Male & 69 & 80 & 160 & 31.3 & 3.4 & no & yes & positive & 33 \\
\hline & avg. & 73.5 & 89.8 & 166 & 32.6 & 5.1 & & & & \\
\hline \multirow{6}{*}{ BMI $>30+$ T2D } & Male & 72 & 98 & 170 & 33.9 & 14.1 & yes & yes & positive & 33 \\
\hline & Male & 73 & 90 & 173 & 30.1 & 4.7 & yes & yes & positive & 34 \\
\hline & Male & 73 & 92 & 162 & 35.1 & 4.5 & yes & yes & positive & 33 \\
\hline & Female & 75 & 92 & 155 & 38.3 & 16.8 & yes & yes & positive & 34 \\
\hline & Male & 67 & 82 & 165 & 30.1 & 5.9 & yes & yes & positive & 34 \\
\hline & avg. & 72 & 90.8 & 165 & 33.5 & 9.2 & & & & \\
\hline
\end{tabular}

Age, Weight, Height, BMI and clinical status when biopsy was taken

${ }^{1)}$ Body Mass Index, weight $(\mathrm{kg}) /[\text { height }(\mathrm{m})]^{2}$

${ }^{2)}$ Homeostatic Model Assessment for Insulin Resistance = Blood Insulin ( $\left.\mu \mathrm{U} / \mathrm{l}\right) \mathrm{x}$ Glucose $(\mathrm{mg} / \mathrm{dl})$

${ }^{3)}$ Type 2 Diabetes 


\section{References}

1. Aibar S, González-Blas CB, Moerman T, Huynh-Thu VA, Imrichova H, Hulselmans G, Rambow F, Marine JC, Geurts P, Aerts J, Van Den Oord J, Atak ZK, Wouters J, Aerts S (2017) SCENIC: Single-cell regulatory network inference and clustering. Nat Methods. doi: 10.1038/nmeth.4463

2. Arranz A, Doxaki C, Vergadi E, De La Torre YM, Vaporidi K, Lagoudaki ED, Ieronymaki E, Androulidaki A, Venihaki M, Margioris AN, Stathopoulos EN, Tsichlis PN, Tsatsanis C (2012) Akt1 and Akt2 protein kinases differentially contribute to macrophage polarization. Proc Natl Acad Sci U S A. doi: 10.1073/pnas.1119038109

3. Baufeld C, Osterloh A, Prokop S, Miller KR, Heppner FL (2016) High-fat diet-induced brain region-specific phenotypic spectrum of CNS resident microglia. Acta Neuropathol. doi: 10.1007/s00401-016-1595-4

4. Bhat NR, Thirumangalakudi L (2013) Increased tau phosphorylation and impaired brain insulin/IGF signaling in mice fed a high fat/high cholesterol diet. J Alzheimer's Dis. doi: 10.3233/JAD-2012-121030

5. Blazquez-Llorca L, Valero-Freitag S, Rodrigues EF, Merchán-Pérez Á, Rodríguez JR, Dorostkar MM, DeFelipe J, Herms J (2017) High plasticity of axonal pathology in Alzheimer's disease mouse models. Acta Neuropathol Commun. doi: 10.1186/s40478-0170415-y

6. Bloom GS (2014) Amyloid- $\beta$ and tau: The trigger and bullet in Alzheimer disease pathogenesis. JAMA Neurol. doi: 10.1001/jamaneurol.2013.5847

7. Bolger AM, Lohse M, Usadel B (2014) Trimmomatic: A flexible trimmer for Illumina sequence data. Bioinformatics. doi: 10.1093/bioinformatics/btu170

8. Bray NL, Pimentel H, Melsted P, Pachter L (2016) Near-optimal probabilistic RNA-seq quantification. Nat Biotechnol 34:525-527. doi: 10.1038/nbt.3519

9. Buccarello L, Grignaschi G, Di Giancamillo A, Domeneghini C, Melcangi RC, Borsello T (2017) Neuroprotective effects of low fat-protein diet in the P301L mouse model of tauopathy. Neuroscience. doi: 10.1016/j.neuroscience.2017.04.027

10. Butovsky O, Jedrychowski MP, Moore CS, Cialic R, Lanser AJ, Gabriely G, Koeglsperger T, Dake B, Wu PM, Doykan CE, Fanek Z, Liu L, Chen Z, Rothstein JD, Ransohoff RM, Gygi SP, Antel JP, Weiner HL (2014) Identification of a unique TGF- $\beta$-dependent molecular and functional signature in microglia. Nat Neurosci. doi: 10.1038/nn.3599 
11. Chen EY, Tan CM, Kou Y, Duan Q, Wang Z, Meirelles G V., Clark NR, Ma'ayan A (2013) Enrichr: Interactive and collaborative HTML5 gene list enrichment analysis tool. BMC Bioinformatics. doi: 10.1186/1471-2105-14-128

12. Chiu S-L, Chen C-M, Cline HT (2008) Insulin receptor signaling regulates synapse number, dendritic plasticity, and circuit function in vivo. Neuron 58:708-19. doi:

10.1016/j.neuron.2008.04.014

13. Dong W, Wang R, Ma LN, Xu BL, Zhang JS, Zhao ZW, Wang YL, Zhang X (2015) Autophagy involving age-related cognitive behavior and hippocampus injury is modulated by different caloric intake in mice. Int J Clin Exp Med

14. Eskelinen MH, Ngandu T, Helkala EL, Tuomilehto J, Nissinen A, Soininen H, Kivipelto M (2008) Fat intake at midlife and cognitive impairment later in life: A population-based CAIDE study. Int J Geriatr Psychiatry. doi: 10.1002/gps.1969

15. Ettcheto M, Petrov D, Pedros I, Alva N, Carbonell T, Beas-Zarate C, Pallas M, Auladell C, Folch J, Camins A (2016) Evaluation of neuropathological effects of a high-fat diet in a presymptomatic Alzheimer's disease stage in APP/PS1 mice. J Alzheimer's Dis. doi: 10.3233/JAD-160150

16. De Felice FG, Ferreira ST (2014) Inflammation, defective insulin signaling, and mitochondrial dysfunction as common molecular denominators connecting type 2 diabetes to Alzheimer Disease. Diabetes

17. Gabbouj S, Natunen T, Koivisto H, Jokivarsi K, Takalo M, Marttinen M, Wittrahm R, Kemppainen S, Naderi R, Posado-Fernández A, Ryhänen S, Mäkinen P, Paldanius KMA, Doria G, Poutiainen P, Flores O, Haapasalo A, Tanila H, Hiltunen M (2019) Intranasal insulin activates Akt2 signaling pathway in the hippocampus of wild-type but not in APP/PS1 Alzheimer model mice. Neurobiol Aging 75:98-108. doi: 10.1016/j.neurobiolaging.2018.11.008

18. Galatro TF, Holtman IR, Lerario AM, Vainchtein ID, Brouwer N, Sola PR, Veras MM, Pereira TF, Leite REP, Möller T, Wes PD, Sogayar MC, Laman JD, Den Dunnen W, Pasqualucci CA, Oba-Shinjo SM, Boddeke EWGM, Marie SKN, Eggen BJL (2017) Transcriptomic analysis of purified human cortical microglia reveals age-associated changes. Nat Neurosci. doi: 10.1038/nn.4597

19. Gokce O, Stanley GM, Treutlein B, Neff NF, Camp JG, Malenka RC, Rothwell PE, Fuccillo M V., Südhof TC, Quake SR (2016) Cellular Taxonomy of the Mouse Striatum as Revealed by Single-Cell RNA-Seq. Cell Rep. doi: 10.1016/j.celrep.2016.06.059

20. Graham LC, Harder JM, Soto I, De Vries WN, John SWM, Howell GR (2016) Chronic consumption of a western diet induces robust glial activation in aging mice and in a mouse model of Alzheimer's disease. Sci Rep. doi: 10.1038/srep21568

21. Grant WB (1999) Dietary links to Alzheimer's disease: 1999 Update. J Alzheimer's Dis

22. Gratuze M, Julien J, Morin F, Calon F, Hébert SS, Marette A, Planel E (2016) High-fat, high-sugar, and high-cholesterol consumption does not impact tau pathogenesis in a mouse model of Alzheimer's disease-like tau pathology. Neurobiol Aging. doi:

10.1016/j.neurobiolaging.2016.07.016

23. Gresa-Arribas N, Viéitez C, Dentesano G, Serratosa J, Saura J, Solà C (2012) Modelling Neuroinflammation In Vitro: A Tool to Test the Potential Neuroprotective Effect of Anti- 
Inflammatory Agents. PLoS One. doi: 10.1371/journal.pone.0045227

24. Hascup ER, Broderick SO, Russell MK, Fang Y, Bartke A, Boger HA, Hascup KN (2019) Diet-induced insulin resistance elevates hippocampal glutamate as well as VGLUT1 and GFAP expression in AßPP/PS1 mice. J Neurochem. doi: 10.1111/jnc.14634

25. Heras-Sandoval D, Pérez-Rojas JM, Hernández-Damián J, Pedraza-Chaverri J (2014) The role of PI3K/AKT/mTOR pathway in the modulation of autophagy and the clearance of protein aggregates in neurodegeneration. Cell Signal

26. Hiltunen M, Khandelwal VKM, Yaluri N, Tiilikainen T, Tusa M, Koivisto H, Krzisch M, Vepsäläinen S, Mäkinen P, Kemppainen S, Miettinen P, Haapasalo A, Soininen H, Laakso M, Tanila H (2012) Contribution of genetic and dietary insulin resistance to Alzheimer phenotype in APP/PS1 transgenic mice. J Cell Mol Med. doi: 10.1111/j.15824934.2011.01384.x

27. Ho L, Qin W, Pompl PN, Xiang Z, Wang J, Zhao Z, Peng Y, Cambareri G, Rocher A, Mobbs C V., Hof PR, Pasinetti GM (2004) Diet-induced insulin resistance promotes amyloidosis in a transgenic mouse model of Alzheimer's disease. FASEB J. doi: 10.1096/fj.03-0978fje

28. Hong S, Beja-Glasser VF, Nfonoyim BM, Frouin A, Li S, Ramakrishnan S, Merry KM, Shi Q, Rosenthal A, Barres BA, Lemere CA, Selkoe DJ, Stevens B (2016) Complement and microglia mediate early synapse loss in Alzheimer mouse models. Science (80- ). doi: $10.1126 /$ science.aad8373

29. Inukai K, Funaki M, Ogihara T, Katagiri H, Kanda A, Anai M, Fukushima Y, Hosaka T, Suzuki M, Shin BC, Takata K, Yazaki Y, Kikuchi M, Oka Y, Asano T (1997) p85a gene generates three isoforms of regulatory subunit for phosphatidylinositol 3-kinase (PI 3kinase), $\mathrm{p} 50 \alpha, \mathrm{p} 55 \alpha$, and $\mathrm{p} 85 \alpha$, with different PI 3-kinase activity elevating responses to insulin. J Biol Chem. doi: 10.1074/jbc.272.12.7873

30. Iqbal K, Liu F, Gong CX (2016) Tau and neurodegenerative disease: The story so far. Nat Rev Neurol

31. Irie F, Fitzpatrick AL, Lopez OL, Kuller LH, Peila R, Newman AB, Launer LJ (2008) Enhanced risk for Alzheimer disease in persons with type 2 diabetes and APOE epsilon4: the Cardiovascular Health Study Cognition Study. Arch Neurol. doi:

10.1001/archneurol.2007.29

32. Jankowsky JL, Fadale DJ, Anderson J, Xu GM, Gonzales V, Jenkins NA, Copeland NG, Lee MK, Younkin LH, Wagner SL, Younkin SG, Borchelt DR (2004) Mutant presenilins specifically elevate the levels of the 42 residue $\beta$-amyloid peptide in vivo: Evidence for augmentation of a 42-specific $\gamma$ secretase. Hum Mol Genet

33. Jeong J-H, Kang E-B (2018) Effects of treadmill exercise on PI3K/AKT/GSK-3 $\beta$ pathway and tau protein in high-fat diet-fed rats. J Exerc Nutr Biochem. doi: 10.20463/jenb.2018.0002

34. Jeong JH, Koo JH, Cho JY, Kang EB (2018) Neuroprotective effect of treadmill exercise against blunted brain insulin signaling, NADPH oxidase, and Tau hyperphosphorylation in rats fed a high-fat diet. Brain Res Bull. doi: 10.1016/j.brainresbull.2018.08.001

35. Jiménez C, Portela RA, Mellado M, Rodríguez-Frade JM, Collard J, Serrano A, Martínez-A C, Avila J, Carrera AC (2000) Role of the PI3K regulatory subunit in the control of actin organization and cell migration. J Cell Biol. doi: 10.1083/jcb.151.2.249

36. Julien C, Tremblay C, Phivilay A, Berthiaume L, Émond V, Julien P, Calon F (2010) High- 
fat diet aggravates amyloid-beta and tau pathologies in the $3 \times \mathrm{Tg}-\mathrm{AD}$ mouse model. Neurobiol Aging. doi: 10.1016/j.neurobiolaging.2008.08.022

37. Junkkari A, Luikku AJ, Danner N, Jyrkkänen HK, Rauramaa T, Korhonen VE, Koivisto AM, Nerg O, Kojoukhova M, Huttunen TJ, Jääskeläinen JE, Leinonen V (2019) The Kuopio idiopathic normal pressure hydrocephalus protocol: initial outcome of 175 patients. Fluids Barriers CNS. doi: 10.1186/s12987-019-0142-9

38. Kang EB, Koo JH, Jang YC, Yang CH, Lee Y, Cosio-Lima LM, Cho JY (2016) Neuroprotective Effects of Endurance Exercise Against High-Fat Diet-Induced Hippocampal Neuroinflammation. J Neuroendocrinol. doi: 10.1111/jne.12385

39. Kemppainen S, Rantamäki T, Jerónimo-Santos A, Lavasseur G, Autio H, Karpova N, Kärkkäinen E, Stavén S, Vicente Miranda H, Outeiro TF, Diógenes MJ, Laroche S, Davis S, Sebastião AM, Castrén E, Tanila H (2012) Impaired TrkB receptor signaling contributes to memory impairment in APP/PS1 mice. Neurobiol Aging. doi:

10.1016/j.neurobiolaging.2011.11.006

40. Keren-Shaul H, Spinrad A, Weiner A, Matcovitch-Natan O, Dvir-Szternfeld R, Ulland TK, David E, Baruch K, Lara-Astaiso D, Toth B, Itzkovitz S, Colonna M, Schwartz M, Amit I (2017) A Unique Microglia Type Associated with Restricting Development of Alzheimer's Disease. Cell 169:1276-1290.e17. doi: 10.1016/j.cell.2017.05.018

41. Kim B, Feldman EL (2012) Insulin resistance in the nervous system. Trends Endocrinol Metab 23:133-141

42. Kim J, Kundu M, Viollet B, Guan KL (2011) AMPK and mTOR regulate autophagy through direct phosphorylation of Ulk1. Nat Cell Biol. doi: 10.1038/ncb2152

43. Kimura T, Fukuda T, Sahara N, Yamashita S, Murayama M, Mizoroki T, Yoshiike Y, Lee B, Sotiropoulos I, Maeda S, Takashima A (2010) Aggregation of detergent-insoluble tau is involved in neuronal loss but not in synaptic loss. J Biol Chem. doi: 10.1074/jbc.M110.136630

44. King D, Yeomanson D, Bryant HE (2015) PI3King the Lock: Targeting the PI3K/Akt/mTOR Pathway as a Novel Therapeutic Strategy in Neuroblastoma. J Pediatr Hematol Oncol

45. Kivipelto M, Ngandu T, Fratiglioni L, Viitanen M, Kåreholt I, Winblad B, Helkala EL, Tuomilehto J, Soininen H, Nissinen A (2005) Obesity and vascular risk factors at midlife and the risk of dementia and Alzheimer disease. Arch Neurol. doi: 10.1001/archneur.62.10.1556

46. Klionsky DJ, Abdalla FC, Abeliovich H et al., (2012) Guidelines for the use and interpretation of assays for monitoring autophagy. Autophagy

47. Knight EM, Martins IVA, Gümüsgöz S, Allan SM, Lawrence CB (2014) High-fat dietinduced memory impairment in triple-transgenic Alzheimer's disease (3xTgAD) mice isindependent of changes in amyloid and tau pathology. Neurobiol Aging. doi: 10.1016/j.neurobiolaging.2014.02.010

48. Kothari V, Luo Y, Tornabene T, O’Neill AM, Greene MW, Geetha T, Babu JR (2017) High fat diet induces brain insulin resistance and cognitive impairment in mice. Biochim Biophys Acta - Mol Basis Dis 1863:499-508. doi: 10.1016/j.bbadis.2016.10.006

49. Krasemann S, Madore C, Cialic R, Baufeld C, Calcagno N, El Fatimy R, Beckers L, O’Loughlin E, Xu Y, Fanek Z, Greco DJ, Smith ST, Tweet G, Humulock Z, Zrzavy T, Conde-Sanroman P, Gacias M, Weng Z, Chen H, Tjon E, Mazaheri F, Hartmann K, Madi A, 
Ulrich JD, Glatzel M, Worthmann A, Heeren J, Budnik B, Lemere C, Ikezu T, Heppner FL, Litvak V, Holtzman DM, Lassmann H, Weiner HL, Ochando J, Haass C, Butovsky O (2017) The TREM2-APOE Pathway Drives the Transcriptional Phenotype of Dysfunctional Microglia in Neurodegenerative Diseases. Immunity. doi: 10.1016/j.immuni.2017.08.008

50. Laitinen MH, Ngandu T, Rovio S, Helkala EL, Uusitalo U, Viitanen M, Nissinen A, Tuomilehto J, Soininen H, Kivipelto M (2006) Fat intake at midlife and risk of dementia and Alzheimer's disease: A population-based study. Dement Geriatr Cogn Disord. doi: $10.1159 / 000093478$

51. Langfelder P, Horvath S (2008) WGCNA: An R package for weighted correlation network analysis. BMC Bioinformatics 9. doi: 10.1186/1471-2105-9-559

52. Langmead B, Salzberg SL (2012) Fast gapped-read alignment with Bowtie 2. Nat Methods. doi: $10.1038 /$ nmeth. 1923

53. Leinonen V, Koivisto AM, Savolainen S, Rummukainen J, Tamminen JN, Tillgren T, Vainikka S, Pyykkö OT, Mölsä J, Fraunberg M, Jääskeläinen JE, Soininen H, Rinne J, Alafuzoff I (2010) Amyloid and tau proteins in cortical brain biopsy and Alzheimer's disease. Ann Neurol. doi: 10.1002/ana.22100

54. Liu C, Li P, Li H, Wang S, Ding L, Wang H, Ye H, Jin Y, Hou J, Fang X, Shu Q (2019) TREM2 regulates obesity-induced insulin resistance via adipose tissue remodeling in mice of high-fat feeding. J Transl Med. doi: 10.1186/s12967-019-2050-9

55. Liu Y, Liu F, Grundke-Iqbal I, Iqbal K, Gong C-X (2011) Deficient brain insulin signalling pathway in Alzheimer's disease and diabetes. J Pathol 225:54-62. doi: 10.1002/path.2912

56. Love MI, Huber W, Anders S (2014) Moderated estimation of fold change and dispersion for RNA-seq data with DESeq2. Genome Biol. doi: 10.1186/s 13059-014-0550-8

57. Luchsinger JA, Tang MX, Shea S, Mayeux R (2002) Caloric intake and the risk of Alzheimer disease. Arch Neurol. doi: 10.1001/archneur.59.8.1258

58. Luikku AJ, Hall A, Nerg O, Koivisto AM, Hiltunen M, Helisalmi S, Herukka SK, Junkkari A, Sutela A, Kojoukhova M, Korhonen V, Mattila J, Lötjönen J, Rummukainen J, Alafuzoff I, Jääskeläinen JE, Remes AM, Solomon A, Kivipelto M, Soininen H, Rauramaa T, Leinonen V (2019) Predicting Development of Alzheimer's Disease in Patients with Shunted Idiopathic Normal Pressure Hydrocephalus. J Alzheimer's Dis. doi: 10.3233/JAD-190334

59. Luyendyk JP, Schabbauer GA, Tencati M, Holscher T, Pawlinski R, Mackman N (2008) Genetic Analysis of the Role of the PI3K-Akt Pathway in Lipopolysaccharide-Induced Cytokine and Tissue Factor Gene Expression in Monocytes/Macrophages. J Immunol. doi: 10.4049/jimmunol.180.6.4218

60. Martiskainen H, Paldanius KMA, Natunen T, Takalo M, Marttinen M, Leskelä S, Huber N, Mäkinen P, Bertling E, Dhungana H, Huuskonen M, Honkakoski P, Hotulainen P, Rilla K, Koistinaho J, Soininen H, Malm T, Haapasalo A, Hiltunen M (2017) DHCR24 exerts neuroprotection upon inflammation-induced neuronal death. J Neuroinflammation 14. doi: 10.1186/s12974-017-0991-6

61. Miller JA, Cai C, Langfelder P, Geschwind DH, Kurian SM, Salomon DR, Horvath S (2011) Strategies for aggregating gene expression data: The collapseRows R function. BMC Bioinformatics. doi: 10.1186/1471-2105-12-322

62. Minkeviciene R, Ihalainen J, Malm T, Matilainen O, Keksa-Goldsteine V, Goldsteins G, 
Iivonen H, Leguit N, Glennon J, Koistinaho J, Banerjee P, Tanila H (2008) Age-related decrease in stimulated glutamate release and vesicular glutamate transporters in APP/PS1 transgenic and wild-type mice. J Neurochem. doi: 10.1111/j.1471-4159.2007.05147.x

63. Moloney AM, Griffin RJ, Timmons S, O'Connor R, Ravid R, O’Neill C (2010) Defects in IGF-1 receptor, insulin receptor and IRS-1/2 in Alzheimer's disease indicate possible resistance to IGF-1 and insulin signalling. Neurobiol Aging. doi:

10.1016/j.neurobiolaging.2008.04.002

64. Montine TJ, Phelps CH, Beach TG, Bigio EH, Cairns NJ, Dickson DW, Duyckaerts C, Frosch MP, Masliah E, Mirra SS, Nelson PT, Schneider JA, Thal DR, Trojanowski JQ, Vinters H V., Hyman BT (2012) National institute on aging-Alzheimer's association guidelines for the neuropathologic assessment of Alzheimer's disease: A practical approach. Acta Neuropathol. doi: 10.1007/s00401-011-0910-3

65. Morris MC, Evans DA, Bienias JL, Tangney CC, Bennett DA, Aggarwal N, Schneider J, Wilson RS (2003) Dietary fats and the risk of incident Alzheimer disease. Arch Neurol. doi: 10.1001/archneur.60.2.194

66. Moser VA, Pike CJ (2017) Obesity accelerates Alzheimer-related pathology in APOE4 but not APOE3 mice. eNeuro. doi: 10.1523/ENEURO.0077-17.2017

67. Nam KN, Mounier A, Wolfe CM, Fitz NF, Carter AY, Castranio EL, Kamboh HI, Reeves VL, Wang J, Han X, Schug J, Lefterov I, Koldamova R (2017) Effect of high fat diet on phenotype, brain transcriptome and lipidome in Alzheimer's model mice. Sci Rep. doi: 10.1038/s41598-017-04412-2

68. Natunen TA, Gynther M, Rostalski H, Jaako K, Jalkanen AJ (2019) Extracellular prolyl oligopeptidase derived from activated microglia is a potential neuroprotection target. Basic Clin Pharmacol Toxicol. doi: 10.1111/bcpt.13094

69. Nott A, Holtman IR, Coufal NG, Schlachetzki JCM, Yu M, Hu R, Han CZ, Pena M, Xiao J, Wu Y, Keulen Z, Pasillas MP, O’Connor C, Nickl CK, Schafer ST, Shen Z, Rissman RA, Brewer JB, Gosselin D, Gonda DD, Levy ML, Rosenfeld MG, McVicker G, Gage FH, Ren B, Glass CK (2019) Brain cell type-specific enhancer-promoter interactome maps and disease-risk association. Science (80- ). doi: 10.1126/science.aay0793

70. Park M, Yi JW, Kim EM, Yoon IJ, Lee EH, Lee HY, Ji KY, Lee KH, Jang JH, Oh SS, Yun CH, Kim SH, Lee KM, Song MG, Kim DH, Kang HS (2015) Triggering receptor expressed on myeloid cells 2 (TREM2) promotes adipogenesis and diet-induced obesity. Diabetes. doi: $10.2337 / \mathrm{db} 13-1869$

71. Paxinos G, Franklin KBJ (2001) Paxinos and Franklin's the Mouse Brain in Stereotaxic Coordinates

72. Peng Q, Malhotra S, Torchia JA, Kerr WG, Coggeshall KM, Humphrey MB (2010) TREM2and DAP12-dependent activation of PI3K requires DAP10 and is inhibited by SHIP1. Sci Signal 3. doi: 10.1126/scisignal.2000500

73. Petrov D, Pedrós I, Artiach G, Sureda FX, Barroso E, Pallàs M, Casadesús G, Beas-Zarate C, Carro E, Ferrer I, Vazquez-Carrera M, Folch J, Camins A (2015) High-fat diet-induced deregulation of hippocampal insulin signaling and mitochondrial homeostasis deficiences contribute to Alzheimer disease pathology in rodents. Biochim Biophys Acta - Mol Basis Dis. doi: 10.1016/j.bbadis.2015.05.004 
74. Pickett EK, Herrmann AG, McQueen J, Abt K, Dando O, Tulloch J, Jain P, Dunnett S, Sohrabi S, Fjeldstad MP, Calkin W, Murison L, Jackson RJ, Tzioras M, Stevenson A, d'Orange M, Hooley M, Davies C, Colom-Cadena M, Anton-Fernandez A, King D, Oren I, Rose J, McKenzie CA, Allison E, Smith C, Hardt O, Henstridge CM, Hardingham GE, Spires-Jones TL (2019) Amyloid Beta and Tau Cooperate to Cause Reversible Behavioral and Transcriptional Deficits in a Model of Alzheimer's Disease. Cell Rep. doi: 10.1016/j.celrep.2019.11.044

75. Portovedo M, Ignacio-Souza LM, Bombassaro B, Coope A, Reginato A, Razolli DS, Torsoni MA, Torsoni AS, Leal RF, Velloso LA, Milanski M (2015) Saturated fatty acids modulate autophagy's proteins in the hypothalamus. PLoS One. doi: 10.1371/journal.pone.0119850

76. Prokop S, Miller KR, Labra SR, Pitkin RM, Hoxha K, Narasimhan S, Changolkar L, Rosenbloom A, Lee VMY, Trojanowski JQ (2019) Impact of TREM2 risk variants on brain region-specific immune activation and plaque microenvironment in Alzheimer's disease patient brain samples. Acta Neuropathol. doi: 10.1007/s00401-019-02048-2

77. Qin W, Zhao W, Ho L, Wang J, Walsh K, Gandy S, Pasinetti GM (2008) Regulation of forkhead transcription factor FoxO3a contributes to calorie restriction-induced prevention of Alzheimer's disease-type amyloid neuropathology and spatial memory deterioration. In: Annals of the New York Academy of Sciences

78. Relkin N, Marmarou A, Klinge P, Bergsneider M, Black PM (2005) Diagnosing Idiopathic Normal-pressure Hydrocephalus. Neurosurgery 57:S2-4-S2-16. doi: 10.1227/01.NEU.0000168185.29659.C5

79. Ritchie ME, Phipson B, Wu D, Hu Y, Law CW, Shi W, Smyth GK (2015) Limma powers differential expression analyses for RNA-sequencing and microarray studies. Nucleic Acids Res. doi: 10.1093/nar/gkv007

80. Rodgers SP, Born HA, Das P, Jankowsky JL (2012) Transgenic APP expression during postnatal development causes persistent locomotor hyperactivity in the adult. Mol Neurodegener. doi: 10.1186/1750-1326-7-28

81. Sah SK, Lee C, Jang JH, Park GH (2017) Effect of high-fat diet on cognitive impairment in triple-transgenic mice model of Alzheimer's disease. Biochem Biophys Res Commun. doi: 10.1016/j.bbrc.2017.08.122

82. Sahara N, Lewis J, DeTure M, McGowan E, Dickson DW, Hutton M, Yen SH (2002) Assembly of tau in transgenic animals expressing P301L tau: Alteration of phosphorylation and solubility. J Neurochem. doi: 10.1046/j.1471-4159.2002.01241.x

83. Salas IH, Weerasekera A, Ahmed T, Callaerts-Vegh Z, Himmelreich U, D’Hooge R, Balschun D, Saido TC, De Strooper B, Dotti CG (2018) High fat diet treatment impairs hippocampal long-term potentiation without alterations of the core neuropathological features of Alzheimer disease. Neurobiol Dis 113:82-96. doi: 10.1016/j.nbd.2018.02.001

84. Schindelin J, Arganda-Carreras I, Frise E, Kaynig V, Longair M, Pietzsch T, Preibisch S, Rueden C, Saalfeld S, Schmid B, Tinevez JY, White DJ, Hartenstein V, Eliceiri K, Tomancak P, Cardona A (2012) Fiji: An open-source platform for biological-image analysis. Nat Methods

85. Serrano-Pozo A, Frosch MP, Masliah E, Hyman BT (2011) Neuropathological alterations in Alzheimer disease. Cold Spring Harb Perspect Med 1. doi: 10.1101/cshperspect.a006189 
86. Seyfried NT, Dammer EB, Swarup V, Nandakumar D, Duong DM, Yin L, Deng Q, Nguyen T, Hales CM, Wingo T, Glass J, Gearing M, Thambisetty M, Troncoso JC, Geschwind DH, Lah JJ, Levey AI (2017) A Multi-network Approach Identifies Protein-Specific Coexpression in Asymptomatic and Symptomatic Alzheimer's Disease. Cell Syst. doi: 10.1016/j.cels.2016.11.006

87. Sims R, Van Der Lee SJ, Naj AC et al., (2017) Rare coding variants in PLCG2, ABI3, and TREM2 implicate microglial-mediated innate immunity in Alzheimer's disease. Nat Genet. doi: $10.1038 / \mathrm{ng} .3916$

88. Sjöholm $\AA$, Nyström T (2006) Inflammation and the etiology of type 2 diabetes. Diabetes Metab Res Rev 22:4-10

89. Son JH, Shim JH, Kim KH, Ha JY, Han JY (2012) Neuronal autophagy and neurodegenerative diseases. Exp Mol Med 44:89-98

90. Soneson C, Love MI, Robinson MD (2016) Differential analyses for RNA-seq: Transcriptlevel estimates improve gene-level inferences [version 2; referees: 2 approved].

F1000Research. doi: 10.12688/F1000RESEARCH.7563.2

91. Streit WJ, Braak H, Xue QS, Bechmann I (2009) Dystrophic (senescent) rather than activated microglial cells are associated with tau pathology and likely precede neurodegeneration in Alzheimer's disease. Acta Neuropathol. doi: 10.1007/s00401-009-0556-6

92. Subramanian A, Tamayo P, Mootha VK, Mukherjee S, Ebert BL, Gillette MA, Paulovich A, Pomeroy SL, Golub TR, Lander ES, Mesirov JP (2005) Gene set enrichment analysis: A knowledge-based approach for interpreting genome-wide expression profiles. Proc Natl Acad Sci U S A. doi: 10.1073/pnas.0506580102

93. Swardfager W, Lanctt K, Rothenburg L, Wong A, Cappell J, Herrmann N (2010) A metaanalysis of cytokines in Alzheimer's disease. Biol Psychiatry 68:930-941. doi: 10.1016/j.biopsych.2010.06.012

94. Takalo M, Haapasalo A, Martiskainen H, Kurkinen KMA, Koivisto H, Miettinen P, Khandelwal VKM, Kemppainen S, Kaminska D, Mäkinen P, Leinonen V, Pihlajamäki J, Soininen H, Laakso M, Tanila H, Hiltunen M (2014) High-fat diet increases tau expression in the brain of T2DM and AD mice independently of peripheral metabolic status. J Nutr Biochem 25:634-641. doi: 10.1016/J.JNUTBIO.2014.02.003

95. Ulland TK, Song WM, Huang SCC, Ulrich JD, Sergushichev A, Beatty WL, Loboda AA, Zhou Y, Cairns NJ, Kambal A, Loginicheva E, Gilfillan S, Cella M, Virgin HW, Unanue ER, Wang Y, Artyomov MN, Holtzman DM, Colonna M (2017) TREM2 Maintains Microglial Metabolic Fitness in Alzheimer's Disease. Cell 170:649-663.e13. doi: 10.1016/j.cell.2017.07.023

96. Valente T, Gella A, Fernàndez-Busquets X, Unzeta M, Durany N (2010) Immunohistochemical analysis of human brain suggests pathological synergism of Alzheimer's disease and diabetes mellitus. Neurobiol Dis. doi: 10.1016/j.nbd.2009.09.008

97. Velázquez KT, Enos RT, Bader JE, Sougiannis AT, Carson MS, Chatzistamou I, Carson JA, Nagarkatti PS, Nagarkatti M, Murphy EA (2019) Prolonged high-fat-diet feeding promotes non-alcoholic fatty liver disease and alters gut microbiota in mice. World J Hepatol. doi: 10.4254/wjh.v11.i8.619

98. Vinuesa A, Bentivegna M, Calfa G, Filipello F, Pomilio C, Bonaventura MM, Lux-Lantos V, 
Matzkin ME, Gregosa A, Presa J, Matteoli M, Beauquis J, Saravia F (2019) Early Exposure to a High-Fat Diet Impacts on Hippocampal Plasticity: Implication of Microglia-Derived Exosome-like Extracellular Vesicles. Mol Neurobiol. doi: 10.1007/s12035-018-1435-8

99. Wakabayashi T, Yamaguchi K, Matsui K, Sano T, Kubota T, Hashimoto T, Mano A, Yamada K, Matsuo Y, Kubota N, Kadowaki T, Iwatsubo T (2019) Differential effects of diet- and genetically-induced brain insulin resistance on amyloid pathology in a mouse model of Alzheimer's disease. Mol Neurodegener. doi: 10.1186/s13024-019-0315-7

100. Wang Y, Cella M, Mallinson K, Ulrich JD, Young KL, Robinette ML, Gilfillan S, Krishnan GM, Sudhakar S, Zinselmeyer BH, Holtzman DM, Cirrito JR, Colonna M (2015) TREM2 lipid sensing sustains the microglial response in an Alzheimer's disease model. Cell. doi: 10.1016/j.cell.2015.01.049

101. Winzell MS, Ahrén B (2004) The high-fat diet-fed mouse: A model for studying mechanisms and treatment of impaired glucose tolerance and type 2 diabetes. In: Diabetes

102. Wullschleger S, Loewith R, Hall MN (2006) TOR signaling in growth and metabolism. Cell

103. Xu WL, Von Strauss E, Qiu CX, Winblad B, Fratiglioni L (2009) Uncontrolled diabetes increases the risk of Alzheimer's disease: A population-based cohort study. Diabetologia. doi: $10.1007 / \mathrm{s} 00125-009-1323-\mathrm{x}$

104. Yamamoto T, Takabatake Y, Takahashi A, Kimura T, Namba T, Matsuda J, Minami S, Kaimori JY, Matsui I, Matsusaka T, Niimura F, Yanagita M, Isaka Y (2017) High-fat dietinduced lysosomal dysfunction and impaired autophagic flux contribute to lipotoxicity in the kidney. J Am Soc Nephrol. doi: 10.1681/ASN.2016070731

105. Yoshii SR, Mizushima N (2017) Monitoring and measuring autophagy. Int J Mol Sci

106. Yuan P, Condello C, Keene CD, Wang Y, Bird TD, Paul SM, Luo W, Colonna M, Baddeley D, Grutzendler J (2016) TREM2 Haplodeficiency in Mice and Humans Impairs the Microglia Barrier Function Leading to Decreased Amyloid Compaction and Severe Axonal Dystrophy. Neuron. doi: 10.1016/j.neuron.2016.05.003

107. Zhang Y, Chen K, Sloan SA, Bennett ML, Scholze AR, O'Keeffe S, Phatnani HP, Guarnieri P, Caneda C, Ruderisch N, Deng S, Liddelow SA, Zhang C, Daneman R, Maniatis T, Barres BA, Wu JQ (2014) An RNA-Sequencing Transcriptome and Splicing Database of Glia, Neurons, and Vascular Cells of the Cerebral Cortex. J Neurosci 34:11929-11947. doi: 10.1523/JNEUROSCI.1860-14.2014

108. Zhao WQ, Townsend M (2009) Insulin resistance and amyloidogenesis as common molecular foundation for type 2 diabetes and Alzheimer's disease. Biochim Biophys Acta Mol Basis Dis

109. Zheng H, Jia L, Liu C-C, Rong Z, Zhong L, Yang L, Chen X-F, Fryer JD, Wang X, Zhang Y, Xu H, Bu G (2017) TREM2 Promotes Microglial Survival by Activating Wnt/ $\beta$-Catenin Pathway. J Neurosci 37:1772-1784. doi: 10.1523/JNEUROSCI.2459-16.2017

110. Zou W, Reeve JL, Liu Y, Teitelbaum SL, Ross FP (2008) DAP12 Couples c-Fms Activation to the Osteoclast Cytoskeleton by Recruitment of Syk. Mol Cell. doi: 10.1016/j.molcel.2008.06.023 
bioRxiv preprint doi: https://doi.org/10.1101/2020.04.07.027292; this version posted April 8, 2020. The copyright holder for this preprint (which was not certified by peer review) is the author/funder. All rights reserved. No reuse allowed without permission. 
bioRxiv preprint doi: https://doi.org/10.1101/2020.04.07.027292; this version posted April 8, 2020. The copyright holder for this preprint (which was not certified by peer review) is the author/funder. All rights reserved. No reuse allowed without permission.
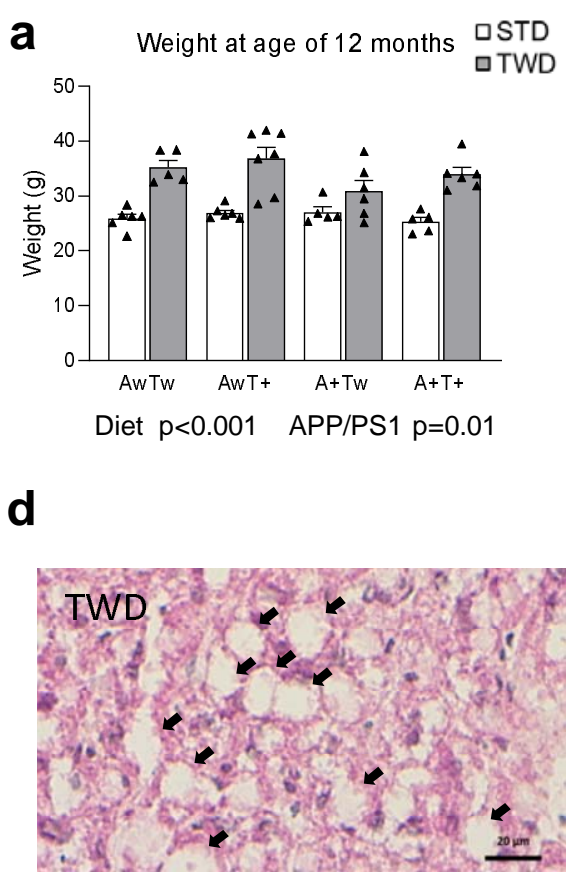

g

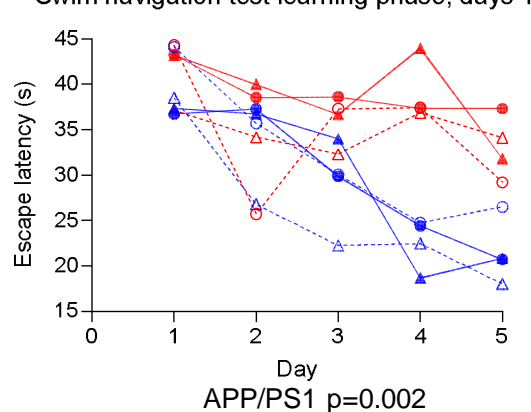

i

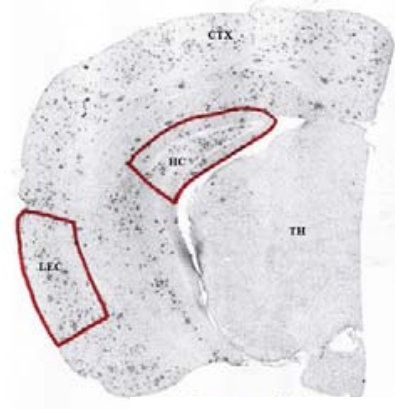

Bregma $-3.16 \mathrm{~mm}$

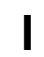

b

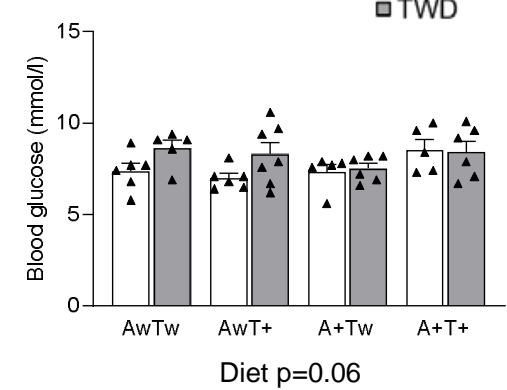

e

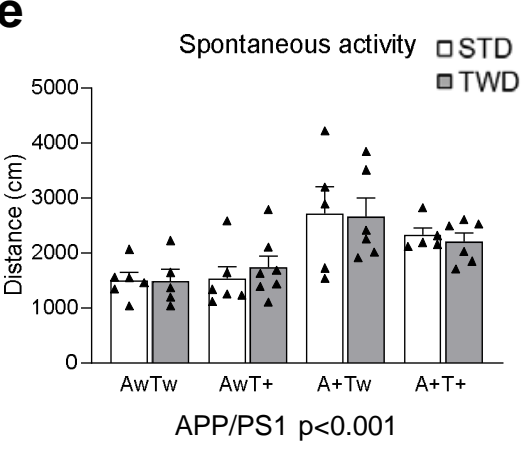

C GTT 30 min $\quad$ aSTD

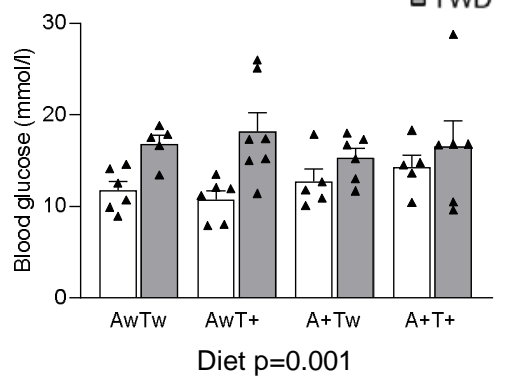

f

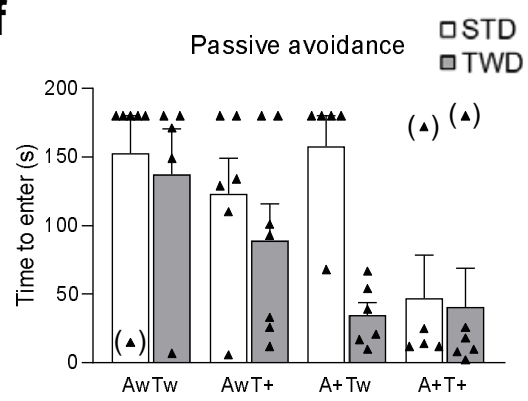

Diet $\mathrm{p}=0.02$ APP/PS1 $\mathrm{p}=0.005$ Tau $\mathrm{p}=0.02$

h

- AwTw STD

- AwTw TWD

A. AwT+ STD

๑. AWT+ TWD

\# A+Tw STD

- A+TW TWD

$A-T+S T D$

- $-A+T+T W D$

Swim navigation probe test for search bias, day 5

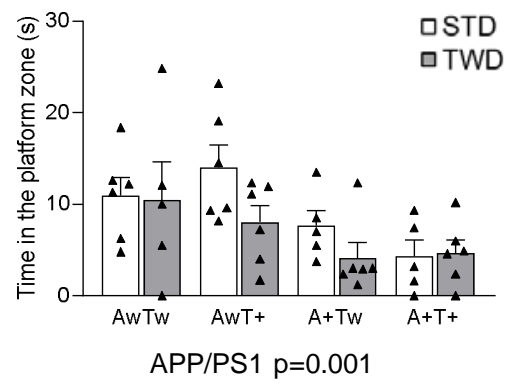

j

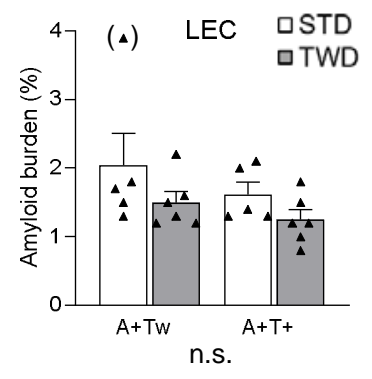

k

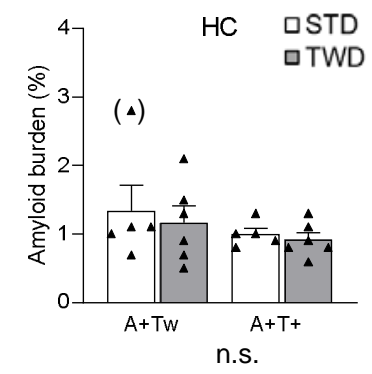

m 口STD

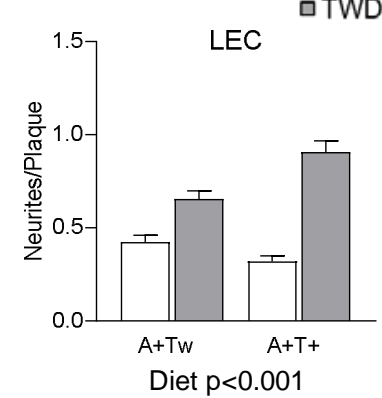


bioRxiv preprint doi: https://doi.org/10.1101/2020.04.07.027292; this version posted April 8, 2020. The copyright holder for this preprint (which

a
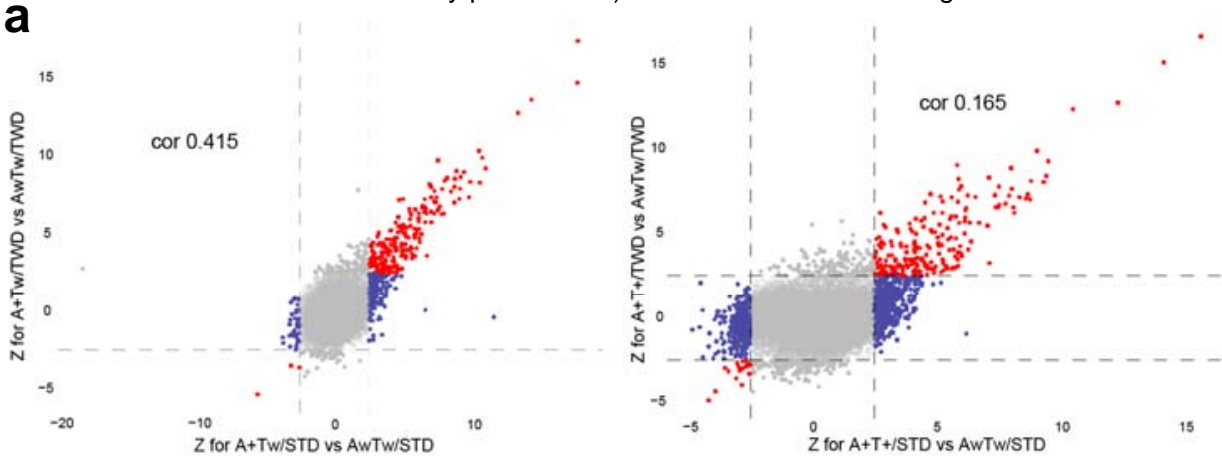

C

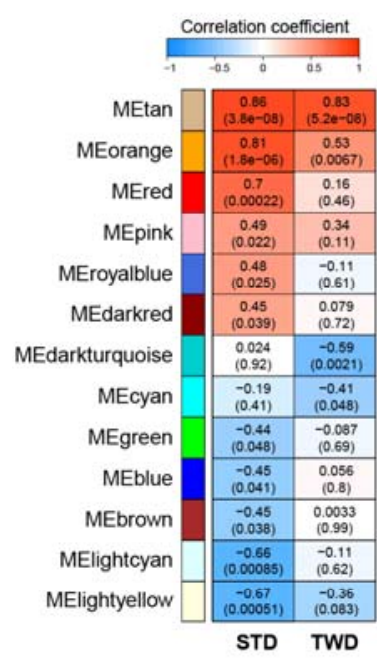

d

Upregulated in $\mathrm{AD}$-associated microglia (Keren-Shaul)

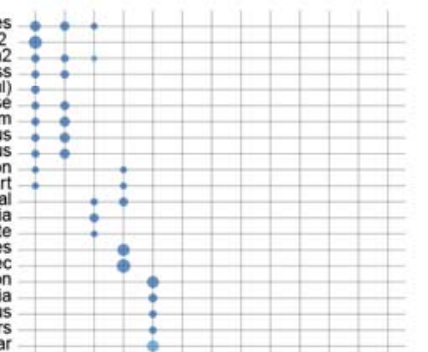

Up-regulated in FoxP1 KO human neural progenitors
Genes correlated (1>0.5) with Trem2
Genes correlated $(r>0.3)$ with Trem2

b

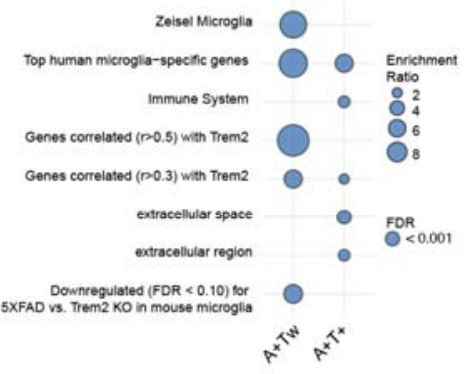

e

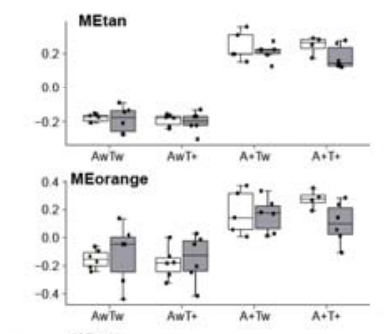

Genes up-renes in striatum Vascula

positive regulation of canonical Wnt signaling wath withway

regulation of canonical Wnt signalige bathway

mitochondrial translation
mitochondrial gene expression

intracellular protein fansport
intracelliular transport
Down-regulated with level of transcriptional noise
DE with level of transcriptional noise

Down-regulated in FoxP1 KO mouse hippocampus

transport vesici
regulation of exocytosis

nervous system development
cell morphogenesis involived in neuron differentiation
multicellular organism developmen

multicellular organism development
cell morphogenesis involved in differentiation

developmental process
Neuronal survival and death
nucleic acid metabolic process

nucleobase-containing compound metabolic process
Up-regulated in FOXP1 $\mathrm{KO}$ mouse striatum

Autism GWAS and highest scoring genes

Zeisel CA1 synaptic membranidal Neurons

AMPA glutamate receptor clusterng
glutamate receptor clustering
adenymetriate cyclase synapse binding

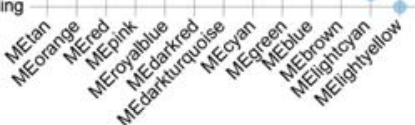

$\mathrm{FDR}>0.1$

$>0.1$
$<0.1$

- $<0.05$

$<0.01$

$<0.001$

Enrichmen

Ratio

- 20

40

60
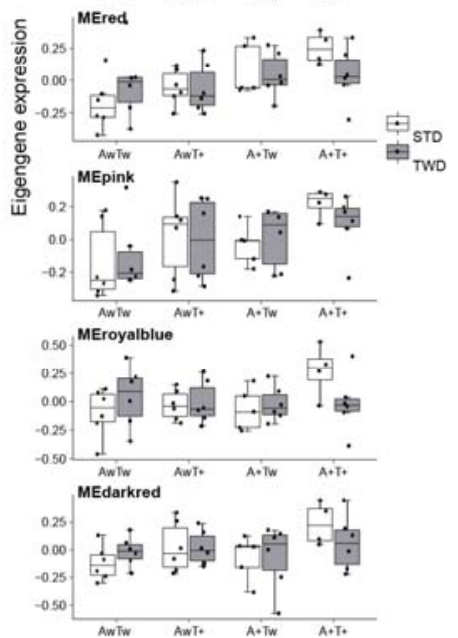

\section{f}

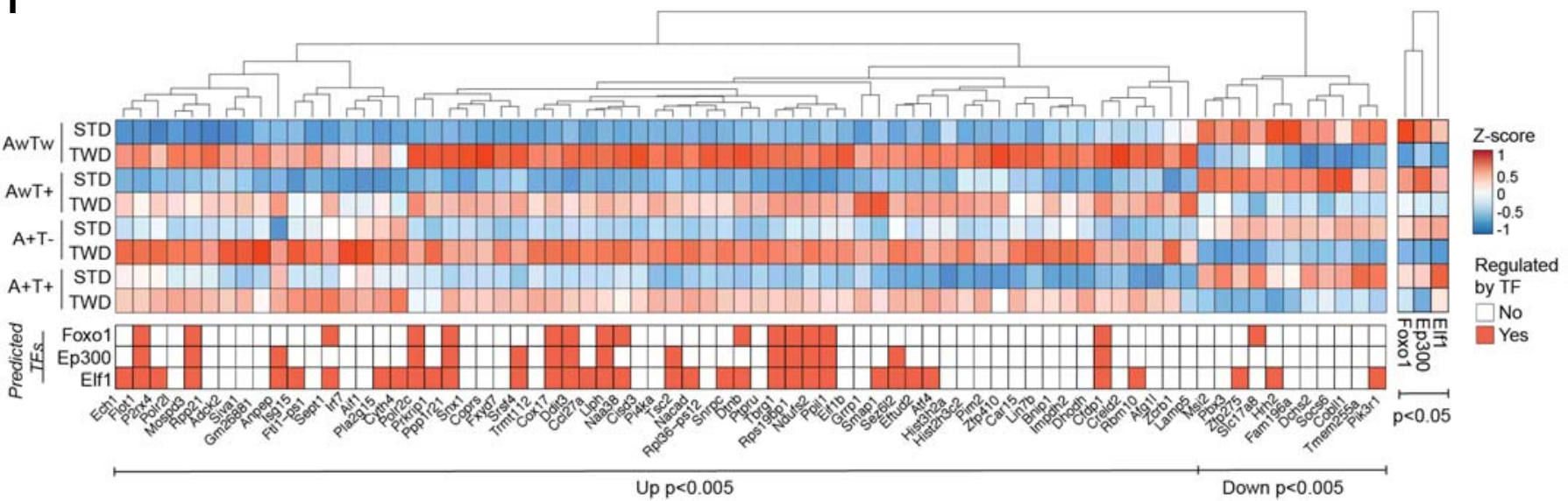


bioRxiv preprint doi: https://doi.org/10.1101/2020.04.07.027292; this version posted April 8, 2020. The copyright holder for this preprint (which was not certified by peer review) is the author/funder. All rights reserved. No reuse allowed without permission.
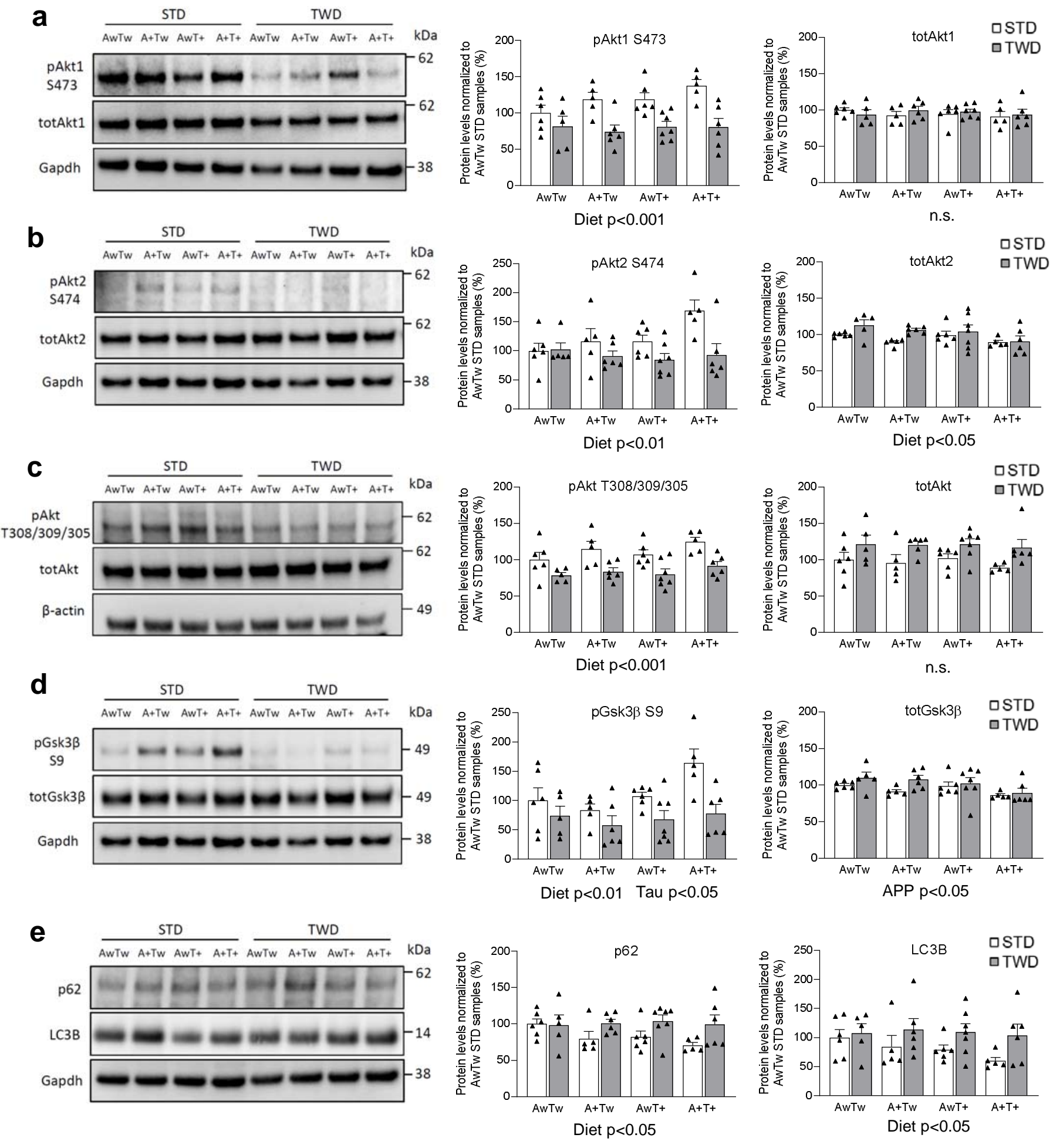
bioRxiv preprint doi: https://doi.org/10.1101/2020.04.07.027292; this version posted April 8, 2020. The copyright holder for this preprint (which

a
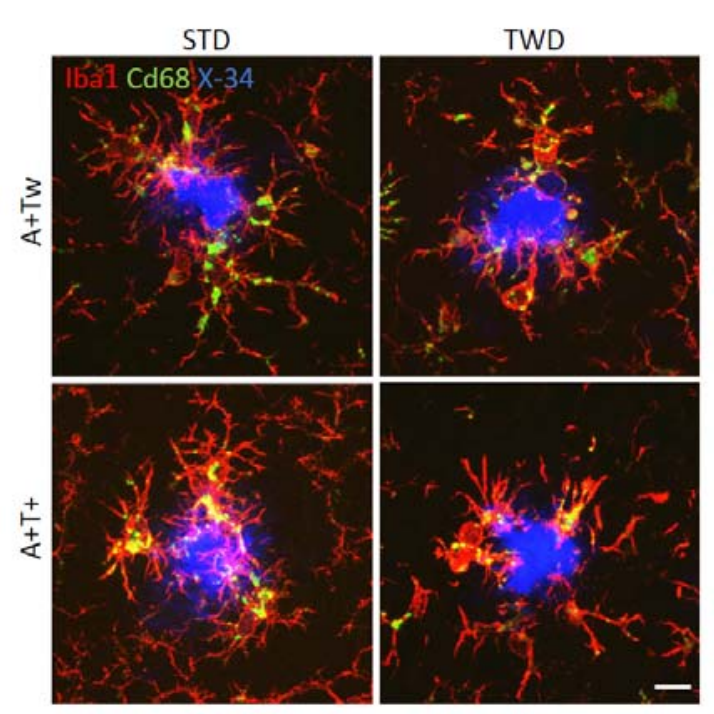

d
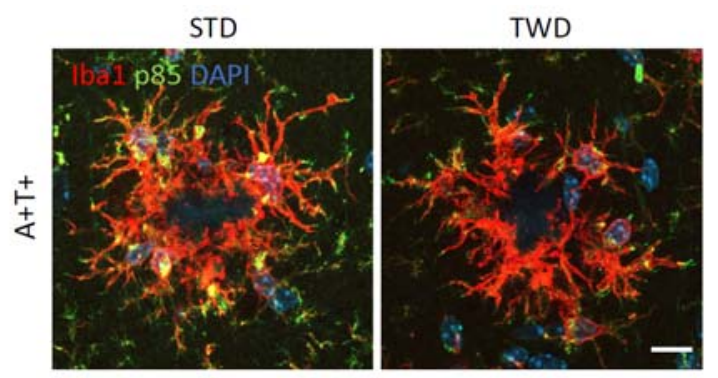

b

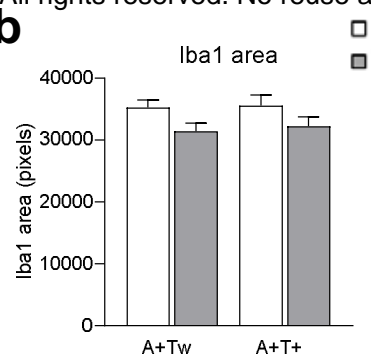

Diet $p<0.05$
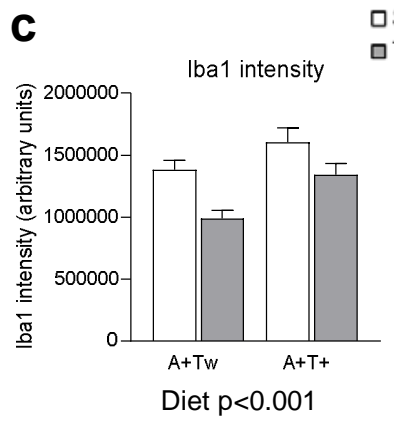

Genotype $p<0.001$
वTD

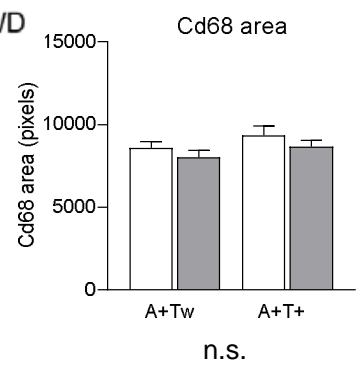

$\square$ STD

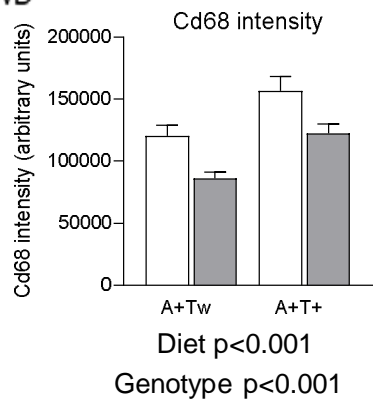

e

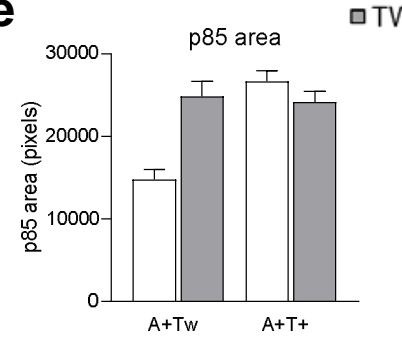

Genotype $p<0.001$

Diet $\mathrm{p}=0.013$

Genotype $x$ Diet $p<0.001$

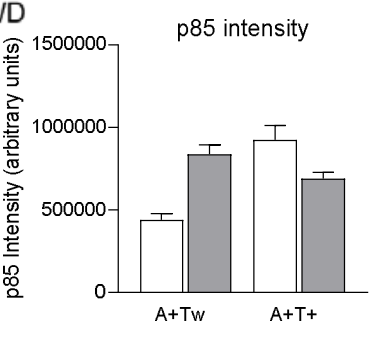

Genotype $p=0.007$

Diet $\mathrm{p}=0.199$

Genotype $x$ Diet $p<0.001$ f

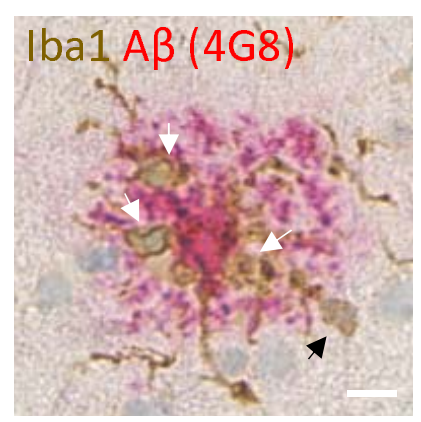

g

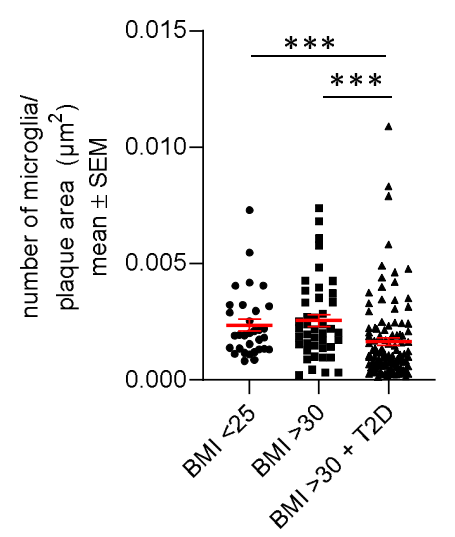

h

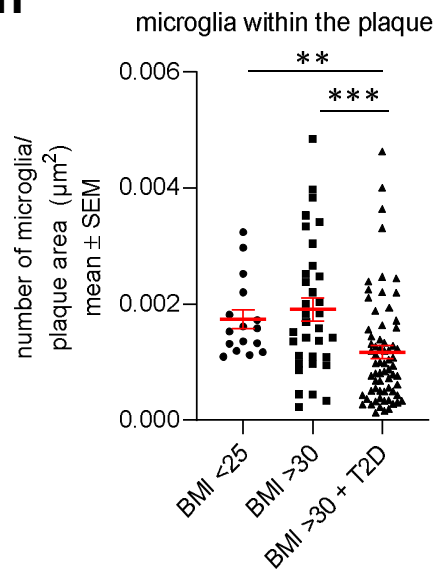


bioRxiv preprint doi: https://doi.org/10.1101/2020.04.07.027292; this version posted April 8, 2020. The copyright holder for this preprint (which was not certified by peer review) is the author/funder. All rights reserved. No reuse allowed without permission.

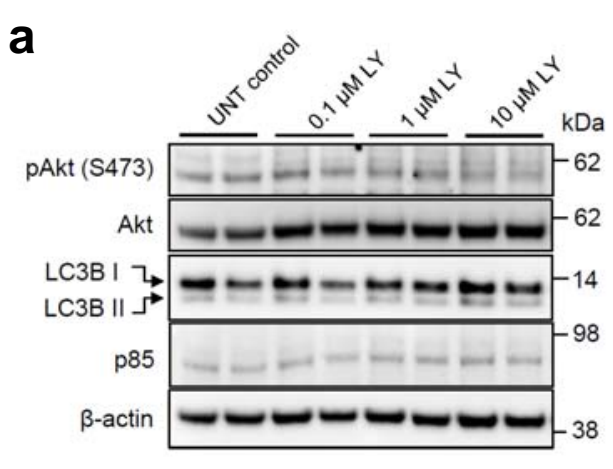

C

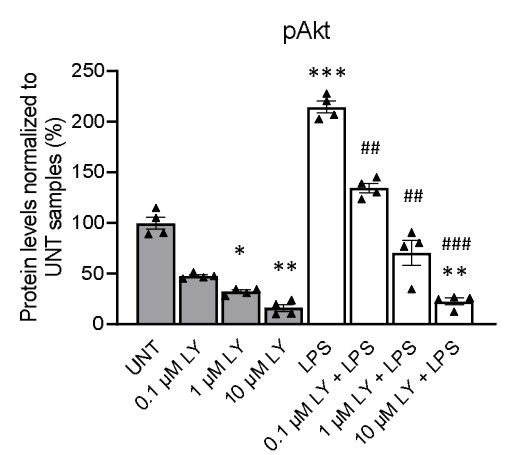

$\mathbf{e}$

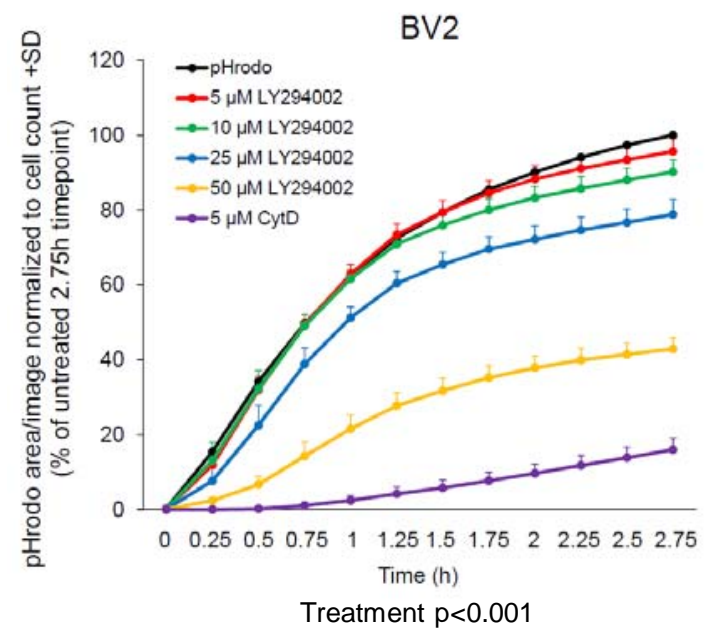

g

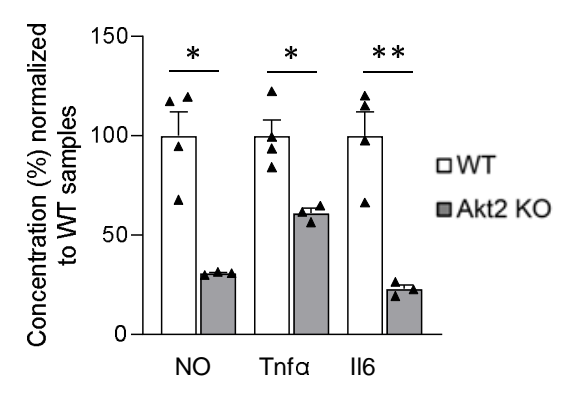

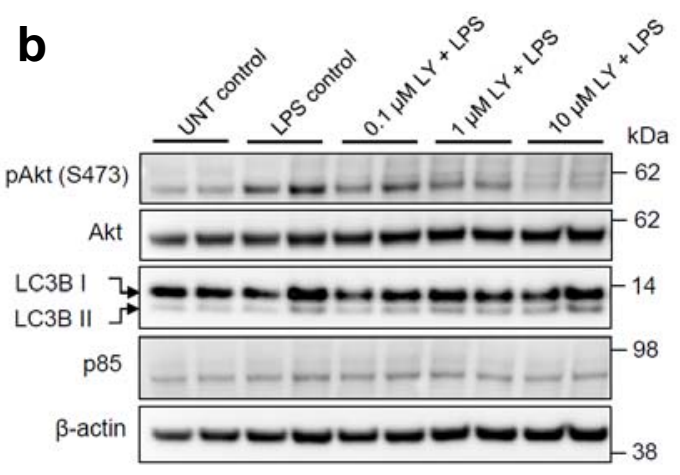

d

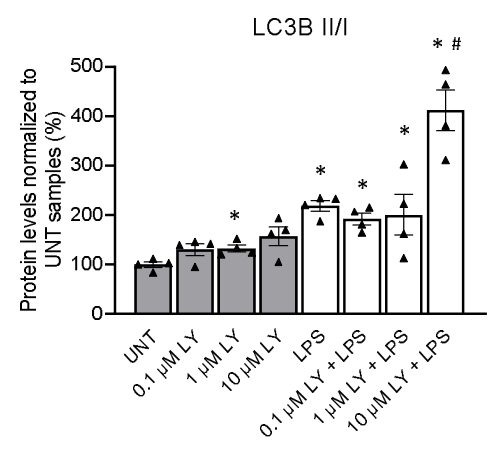

f

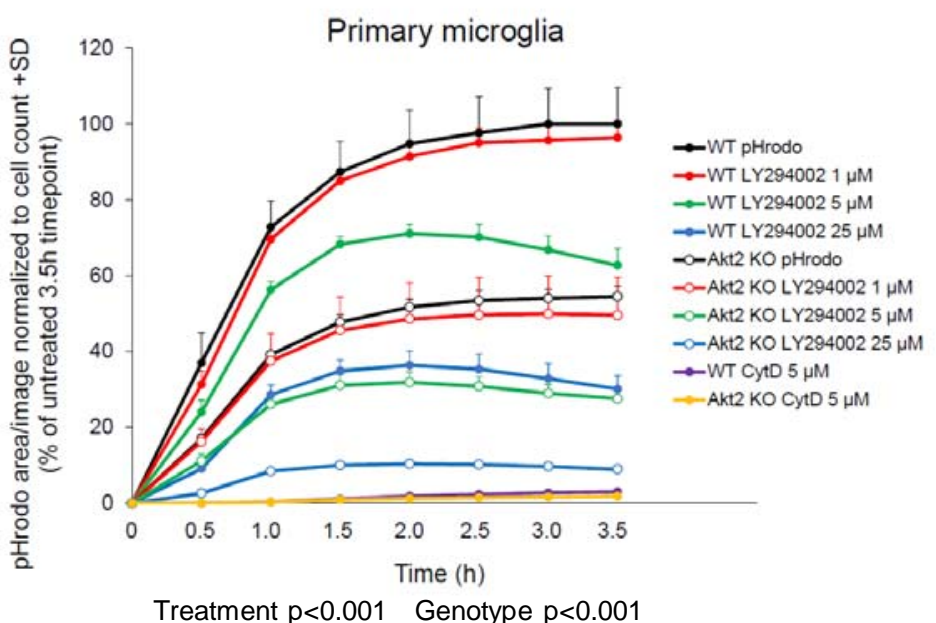

Figure 5 
bioRxiv preprint doi: https://doi.org/10.1101/2020.04.07.027292; this version posted April 8, 2020. The copyright holder for this preprint (which was not certified by peer review) is the author/funder. All rights reserved. No reuse allowed without permission.

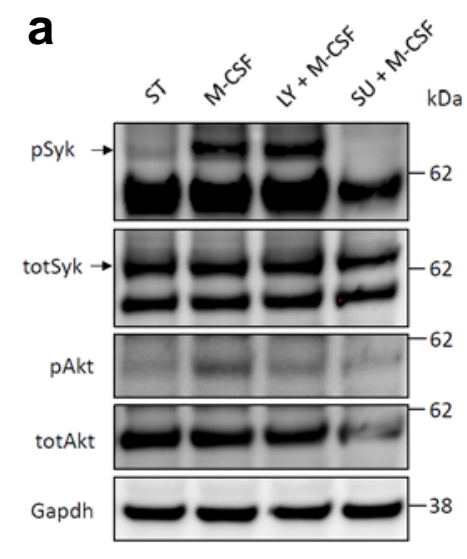

b

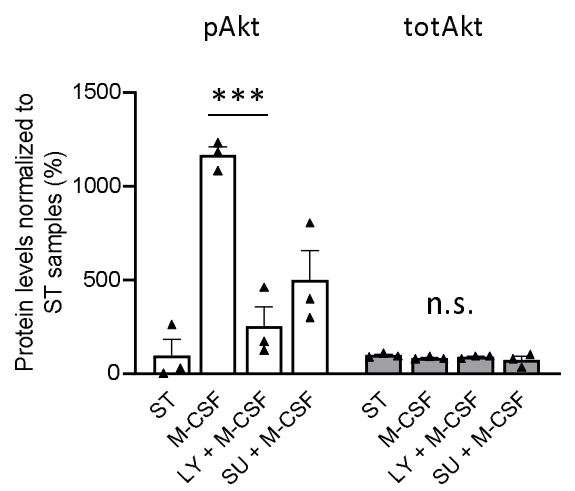

C

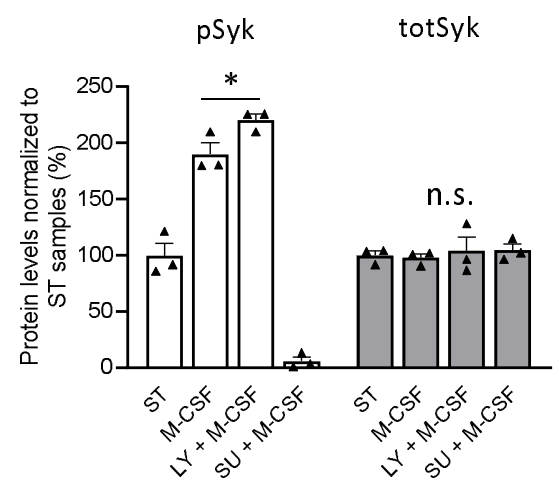

d

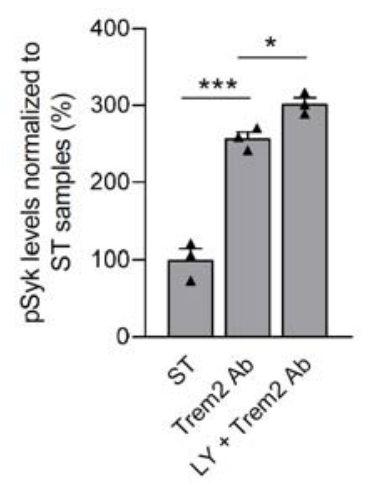

Figure 6 